\title{
LA PROTECCIÓN INTERNACIONAL DE LOS DERECHOS SOCIALES. A PROPÓSITO DE LA RATIFICACIÓN ESPAÑOLA DEL PROTOCOLO FACULTATIVO DEL PACTO DE DERECHOS ECONÓMICOS, SOCIALES Y CULTURALES DE 2008
}

\author{
Ana Gemma López MARTíN \\ Profesora Titular de Derecho \\ Internacional Público. UCM \\ anagema@der.ucm.es
}

\begin{abstract}
RESUMEN
Los derechos económicos, sociales y culturales han sido objeto de escasa atención y desarrollo por los Estados que, tradicionalmente, han negado su justiciabilidad. Esto ha supuesto que los tratados que reconocen estos derechos no contengan adecuados mecanismos de control de su aplicación. El Protocolo Adicional a la Carta Social Europea de 1995, y, sobre todo, el Protocolo Facultativo del Pacto de Derechos Económicos, Sociales y Culturales de 2008 - ratificado por España-constituyen un paso adelante en la protección de estos derechos en el ámbito internacional.
\end{abstract}

Palabras clave: derechos económicos, sociales y culturales, derechos humanos, Naciones Unidas, Consejo de Europa, mecanismos de control, reclamación individual, Derecho internacional.

\section{ABSTRACT}

The economic, social and cultural rights have received little attention and development by States that have traditionally denied their justiciability. This has meant that the treaties that recognize these rights do not contain adequate mechanisms for monitoring their implementation. The Additional Protocol to the European Social Charter of 1995, and, above all, the Optional Protocol to the Covenant on Economic, Social and Cultural Rights 2008, ratified by Spain, constitute a step forward in protecting these rights in the international arena.

Keywords: economic, social and cultural rights, human rights, United Nations, Council of Europe, monitoring mechanisms, individual claim, International Law.

\section{ZUSAMMENFASSUNG}

Die wirtschaftlichen, sozialen und kulturellen Rechte wurden bisher von den Staten wenig beachtet und entwickelt, da die Staaten traditionellerweise die 
Fäbigkeit ibrer Rechtfertigung leugnen. Dies hat dazu geführt, dass die Abkommen, die diese Rechte anerkennen, über keine adäquaten Kontrollmechanismen bezüglich ibrer Anwendung verfügen. Das Zusatzprotokoll zur Europäischen Sozialcharta 1995, insbesondere das Fakultativprotokoll zum Internationalen Pakt über wirtschaftliche, soziale und kulturelle Rechte 2008, von Spanien ratifiziert, stellt bezüglich des Schutzes dieser Rechte im internationalem Bereich einen Schritt nach vorne dar.

Schlüsselwörter: wirtschaftliche, soziale und kulturelle Rechte, Menschenrechte, Vereinte Nationen, Europarat, Kontrollmechanismen, Einzeleinklage, Internationales Recht.

SUMARIO: I. INTRODUCCIÓN.-II. LOS DERECHOS ECONÓMICOS, SOCIALES Y CULTURALES EN EL MARCO JURÍDICO-INTERNACIONAL Y SUS MECANISMOS DE GARANTÍA Y CONTROL DE APLICACIÓN.-1. Los derechos colectivos en el ámbito universal.-2. Los derechos económicos, sociales y culturales en el ámbito regional.-III. LOS MECANISMOS DE PROTECCIÓN DE LOS DERECHOS SOCIOECONÓMICOS EN EL MARCO DE LAS NACIONES UNIDAS: EL PROTOCOLO FACULTATIVO DEL PACTO DE DERECHOS ECONÓMICOS, SOCIALES Y CULTURALES DE 10 DE DICIEMBRE DE 2008.-1. El largo camino recorrido hasta la adopción del Protocolo.-2. Algunos aspectos destacables de este Protocolo.-3. Las denuncias interestatales y la investigación confidencial.-4. Las reclamaciones individuales por violación del Pacto de Derechos Económicos, Sociales y Culturales.-IV. EL SISTEMA DE CONTROL DEL CONSEJO DE EUROPA: LA CARTA SOCIAL EUROPEA Y SUS PROTOCOLOS.-1. Los órganos de control.-2. La técnica de los informes estatales periódicos.-3. El mecanismo de las reclamaciones colectivas.-V. UNA VALORACIÓN FINAL A MODO DE CONCLUSIÓN.

\section{INTRODUCCIÓN}

El 23 de septiembre de 2010, España depositó su instrumento de ratificación del Protocolo Facultativo del Pacto de Derechos Económicos, Sociales y Culturales de 10 de diciembre de 2008 ${ }^{1}$; hecho que se enmarca dentro del Plan de Derechos Humanos de España, aprobado por el Consejo de Ministros el 12 de diciembre de 2008 (MEDIDA 2) ${ }^{2}$. La ratificación de un tratado internacional no constituye en sí misma un hecho de especial relevancia que merezca, por ende, una referencia particular, habida cuenta

${ }^{1}$ Previamente, España — junto con otros diecinueve Estados- había firmado el texto de dicho Protocolo en la ceremonia oficial que a tal efecto tuvo lugar el 24 de septiembre de 2009 en la sede de Naciones Unidas en Nueva York.

${ }^{2}$ El Plan de Derechos Humanos puede consultarse en la siguiente dirección: http:// www1.mpr.es/uploads/media/pdf/2/ddhhes 1260787618.pdf. 
de que tal acto forma parte de la rutina de las relaciones internacionales y la política exterior de los Estados. Sin embargo, esta ratificación española a la que nos referimos merece una atención específica por dos datos sumamente significativos e interrelacionados.

El primero y fundamental es que el Protocolo Facultativo del Pacto de Derechos Económicos, Sociales y Culturales de 2008 es el primer tratado de derechos humanos que recoge la técnica de las denuncias individuales - $\mathrm{y}$ también de las denuncias interestatales- en caso de violación de alguno de los derechos socioeconómicos recogidos en el Pacto, lo que convierte a este Protocolo en un auténtico hito y en un avance en la protección de esta particular categoría de derechos. Y esto es así porque debemos tener presente que para mejorar y asegurar el disfrute efectivo de los derechos humanos, además del reconocimiento y proclamación de los mismos, es primordial desarrollar mecanismos de garantía y control que los protejan de forma eficaz.

En esta línea, el proceso histórico de generalización y expansión de la protección internacional de los derechos humanos ha venido marcado por el fenómeno de la multiplicación de mecanismos de control de distinta naturaleza jurídica y diferentes efectos que coexisten, tanto a nivel universal, como a nivel regional. Una de las notas más destacables en el desarrollo histórico de tales mecanismos, la constituye la progresiva consolidación de la capacidad procesal del individuo para poder reclamar internacionalmente la violación de sus derechos fundamentales. En esta línea, si hubo un tiempo allá en la década de los años cincuenta — cuando empezaron a instaurarse las primeras técnicas que reconocían la legitimación del individuo para presentar denuncias contra un Estado por la violación de sus derechos fundamentales - en el que uno se preguntaba acerca del posible papel de las quejas individuales y hasta qué punto las mismas podrían llegar a ser eficaces para proteger los derechos humanos, su aplicación primero por el Convenio de Roma de 19503. y su inclusión después en el Pacto de Naciones Unidas de Derechos Civiles y Políticos de 1966, demostraron en un corto periodo de tiempo que dicha técnica resultaba vital en la eficacia de la protección de los derechos humanos.

Hoy día, sesenta años después, no hay duda de que el derecho de reclamación individual —independientemente de la terminología adoptada, ya

${ }^{3}$ El Convenio Europeo para la Protección de los Derechos Humanos y de las Libertades Fundamentales de 4 noviembre 1950, primer texto convencional que recoge la posibilidad de denuncia individual, entró en vigor en 1953. Por su parte, la Comisión Interamericana de Derechos Humanos, órgano igualmente competente para conocer de comunicaciones de particulares, fue creada por el Consejo de la OEA a finales de 1959. 
sea comunicación, petición, queja, denuncia o demanda- constituye la piedra angular de la protección de los derechos humanos, conformando la técnica de control más avanzada. El enfrentamiento entre los individuos lesionados - las víctimas - y los Estados presuntamente violadores constituye, sin duda, la esencia de tal protección. Es a través del ejercicio del derecho de petición individual como se garantiza el acceso directo del particular a la justicia a nivel internacional, y cómo el individuo afirma su posición como sujeto del Derecho internacional de los derechos humanos. En este sentido, la institución de la demanda o denuncia individual que permite a la propia víctima que sufre la violación de sus derechos demandar o denunciar, según el caso, al Estado supuestamente infractor constituye el mecanismo de control más avanzado y eficaz. En este sentido, señalaba Cançado Trindade que el acceso de los individuos a los órganos internacionales de protección y el reconocimiento de su capacidad procesal internacional en casos de violación de derechos humanos es, seguramente, uno de los mayores logros de la protección internacional de los derechos fundamentales y el mayor legado de la ciencia jurídica del siglo $\mathrm{xx}^{4}$. Sin el derecho de reclamación individual los derechos universalmente consagrados y reconocidos se reducirían a poco más que letra muerta.

Siendo esto así resulta que, hasta ahora, el mecanismo de la reclamación individual sólo era posible con relación a los derechos civiles y políticos, quedando excluida para los derechos socioeconómicos que, de esta forma, parecían convertirse en una especie de derechos de «segunda categoría», de «hermanos pobres» de aquéllos. El Protocolo de 2008 termina con esta evidente «desigualdad», reconociendo la posibilidad de presentar denuncias individuales contra Estados en caso de supuesta violación de los derechos económicos, sociales y culturales, con lo que se consagra, por fin, el principio de indivisibilidad e interconexión de todos los derechos humanos que proclamó en su día la Declaración Universal de los Derechos Humanos de 1948.

Pero no basta con la mera adopción de este Tratado, es necesario que los Estados se obliguen por el mismo, demostrando así su grado de implicación en la protección de estos derechos. Ahí es donde chocamos con el muro infranqueable de la ausencia de voluntad política de los Estados, pues, hasta la fecha, tan sólo tres Estados han ratificado el Pro-

${ }^{4}$ Vid. A. A. CAnÇADO TRIndade, «The Procedural Capacity of the Individual as subject of International Human Rights Law: Recent Development», en Karel Vasak amicorum liber. Los derechos bumanos ante el siglo XXI, Bruselas, 1999, pp. 531-532. 
tocolo de 2008. Ahora bien, y éste es el segundo dato a reseñar, España es precisamente uno de esos tres Estados comprometidos que se ha obligado por este Protocolo 5 , lo cual evidencia la clara y decidida apuesta del Estado español en la defensa de todos los derechos humanos. Es precisamente en estos gestos donde radica, como decimos, la auténtica voluntad política de un Estado, pues no basta con llenarse la boca de buenas intenciones, proclamando una argüida defensa de los derechos humanos; es necesario confirmar las palabras con hechos y, en este sentido, la mejor prueba de un auténtico compromiso pasa por someterse a los mecanismos de control existentes, a través de los cuales se asegure que la protección es efectiva. Ése es el objetivo del Protocolo de 2008, y sólo aquellos que se obliguen por él demostrarán estar verdaderamente comprometidos con la protección de los derechos sociales, económicos y culturales. Tal es, sin duda, el caso de España.

\section{LOS DERECHOS ECONÓMICOS, SOCIALES Y CULTURALES EN EL MARCO JURÍDICO-INTERNACIONAL Y SUS MECANISMOS DE GARANTÍA Y CONTROL DE APLICACIÓN}

No es sino hasta 1945 cuando los Estados toman conciencia de la necesidad de regular a nivel internacional la protección y promoción de los derechos humanos, siendo la Carta de la Organización de las Naciones Unidas de 26 de junio de 1945 el primer tratado internacional en el que se proclama la firme intención de «reafirmar la fe en los derechos fundamentales del hombre, en la dignidad y el valor de la persona humana, en la igualdad de derechos de hombres y mujeres, y de las naciones grandes y pequeñas», además de consagrar como uno de sus propósitos el de lograr «el desarrollo y estímulo del respeto a los derechos humanos y a las libertades fundamentales de todos, sin hacer distinción por motivos de raza, sexo, idioma o religión». A partir de entonces, el desarrollo de lo que se ha dado en llamar el Derecho Internacional de los Derechos Humanos ha sido vertiginoso, si bien es cierto que con una suerte desigual; pues, mientras los derechos civiles y políticos han sido objeto de un profusa regulación tanto a nivel universal como en el ámbito regional, contando con numerosos tratados

\footnotetext{
${ }^{5}$ Los otros dos Estados que junto con España se han obligado por el Protocolo Facultativo de 2008 son Ecuador y Mongolia.
} 
internacionales que no sólo reconocen sin fisuras estos derechos, sino que además articulan eficaces mecanismos de control de su respeto, los derechos económicos, sociales y culturales, en cambio, han contado con una menor atención, siendo escasos y poco eficientes los sistemas que garantizan su aplicación y cumplimiento, lo que genera la sensación de que éstos han pasado a ser «hermanos pobres» de aquéllos.

Afortunadamente, los Estados parecen estar tomando conciencia poco a poco de lo infundada que resulta esta situación, y de forma progresiva, aunque lenta, se están adoptando nuevas normas internacionales que tienden a la equiparación de ambas categorías de derechos. El primer paso lo dio el Consejo de Europa con la adopción del Protocolo Adicional de la Carta Social Europea de 1995, por el que se establece un sistema de reclamaciones colectivas en caso de violación de los derechos recogidos en la Carta. El siguiente y más trascendente lo ha dado Naciones Unidas al adoptar en 2008 el Protocolo Facultativo del Pacto de Derechos Económicos, Sociales y Culturales, un tratado que, como ya hemos señalado, va más allá al reconocer la posibilidad de denuncia individual por la violación de estos derechos. Ambos textos jurídicos se erigen en referentes de la protección internacional de los derechos económicos, sociales y culturales, cuyo panorama global pasamos a esbozar ${ }^{6}$.

\section{Los derechos colectivos en el ámbito universal}

\subsection{La protección en el sistema de las Naciones Unidas}

El 10 de diciembre de 1948, la Asamblea General de las Naciones Unidas reunida en el Palais Chaillot de París aprobó, por cuarenta y ocho votos a favor, ocho abstenciones y ningún voto en contra ${ }^{7}$, la Resolución 217 A (III) que proclama la «Declaración Universal de los Derechos del Hombre» ${ }^{8}$. Redactada como «un ideal común por el que todos los pueblos y naciones deben esforzarse», en la Declaración se estable-

${ }^{6}$ Desde la perspectiva aplicada de la práctica procesal, en la que se puede observar en detalle el avance operado en la justiciabilidad de los derechos económicos, sociales y culturales, tanto a nivel comparado como ante instancias internacionales, resulta recomendable la consulta del informe InTERNATIONAL COMMission OF JuRISTS, «Courts and the Legal Enforcement of Economic, Social and Cultural Rights: Comparative experiences of justiciability», Human Rights and Rules of Law Series, núm. 2, 2008.

7 Dos Estados se ausentaron en el momento de la votación.

${ }^{8}$ En 1951 la Asamblea General a través de la Resolución 548 (VI) decidió que los térmi- 
cen, por primera vez en la historia de la humanidad, claramente los derechos civiles, políticos, económicos, sociales y culturales básicos de los que todos los seres humanos deben gozar, y que se consideran universales, indivisibles e interdependientes.

Tras esta Declaración, era intención de la Asamblea General elaborar y adoptar un único tratado internacional que positivizara todos los derechos humanos, en coherencia con la Declaración. De esta forma, la Asamblea solicitó a la Comisión de Derechos Humanos que preparara un proyecto de tan solo un texto convencional que precisara en términos jurídicos los derechos reconocidos en la Declaración. Sin embargo, la Comisión se encontró con dos dificultades: una, la de precisar los derechos económicos, sociales y culturales; otra, establecer un único sistema de control de cumplimiento de todos los derechos, habida cuenta la resistencia de los Estados a instaurar un mecanismo de supervisión respecto de los derechos económicos, sociales y culturales. Y ello por considerar a los derechos socioeconómicos como no justiciables, por entender que son derechos progresivos por naturaleza y que están formulados en un lenguaje demasiado impreciso para poder ser aplicables judicialmente. Una afirmación que a nosotros se nos antoja de una simplificación excesiva y carente de fundamento, pues no hay nada inherente en estos derechos que impida la determinación judicial de su contenido.

Pero lo cierto es que, ante el muro infranqueable de la nula voluntad política de querer precisar jurídicamente y controlar los derechos socioeconómicos con el que chocó la Comisión de Derechos Humanos, el Consejo Económico y Social (ECOSOC) manifestó en 1951 que habría que reconsiderar la idea unitaria inicial de la Asamblea General. Esto llevó, finalmente, a elaborar dos textos convencionales separados, con derechos distintos en cada uno de ellos y diferentes sistemas de control de su aplicación: el Pacto de Derechos Civiles y Políticos, por un lado, y el Pacto de Derechos Económicos, Sociales y Culturales, por otro; ambos adoptados el 16 de diciembre de $1966^{\circ}$.

nos «derechos del hombre» fueran sustituidos por «derechos humanos» en todas las publicaciones de Naciones Unidas relativas a la Declaración Universal.

Debemos señalar que éste no es el primer instrumento internacional que reconoce los derechos humanos. Unos meses antes, el 2 de mayo de 1948, la Organización de Estados Americanos adoptó la «Declaración Americana de Derechos y Deberes del Hombre».

9 El Pacto de Derechos Económicos, Sociales y Culturales fue aprobado por la Resolución de la Asamblea General 2200 (XXI), entrando en vigor el 3 de enero de 1976. España depositó su instrumento de ratificación el 27 de abril de 1977 (BOE, núm. 103, de 30 de abril de 1977). Actualmente cuenta con 160 Estados Partes. 
El Pacto de Derechos Económicos, Sociales y Culturales está constituido por un total de treinta y un artículos, y en él se reconocen los siguientes derechos socioeconómicos: el derecho al trabajo (art. 6), el derecho a disfrutar de condiciones de trabajo equitativas y satisfactorias (art. 7), la libertad de fundar sindicatos y afiliarse a ellos y el derecho de huelga (art. 8), el derecho a la seguridad social y a la asistencia social (art. 9), la protección y asistencia a la familia (art. 10), derecho a un nivel de vida adecuado y a medios de subsistencia, incluso alimentación, vestido y vivienda (art. 11), derecho a la salud física y mental (art. 12), derecho a la educación y formación profesional (arts. 13 y 14), y el derecho a participar en la vida cultural y a gozar de los beneficios del progreso científico (art. 15).

Por lo que se refiere a los mecanismos de control, el Pacto de Derechos Civiles y Políticos prevé dos sistemas de garantía de aplicación, uno obligatorio - informes estatales periódicos- y otro facultativo - denuncias interestatales-, a los que se suma el de las comunicaciones individuales que regula el Primer Protocolo Facultativo del Pacto de Derechos Civiles y Políticos de 16 de diciembre de 1966. Frente a este «tridente» garantista, el Pacto de Derechos Económicos, Sociales y Culturales (PDESC) tan sólo recoge en los arts. 16 y 17 la técnica clásica y poco efectiva de los informes estatales periódicos acerca de las medidas que han adoptado con el fin de asegurar el respeto a los derechos reconocidos en el Pacto, que en los primeros años de vigencia se mostró sumamente ineficaz.

Con la finalidad de mejorar el deficiente funcionamiento del sistema, el ECOSOC procedió a crear un órgano específico de control del PDESC -el Comité de Derechos Económicos, Sociales y Culturales ${ }^{10}$ — siguiendo el modelo del ya existente Comité de Derechos Humanos. Este Comité está integrado por dieciocho miembros, expertos de reconocida competencia en materia de derechos humanos que actúan a título personal y son elegidos por el ECOSOC por un periodo de cuatro años con posibilidad de reelección. La función del Comité consiste en vigilar la aplicación del Pacto por medio de un diálogo constructivo con los Estados, definiendo con claridad los objetivos perseguidos a través de la técnica de los informes y la forma de presentar estos últimos ${ }^{11}$. Con tal fin, en 1999, el Comité elaboró unas directrices que contienen indicaciones precisas sobre la información que deben proporcionarle los Estados. De esta forma, cada Estado debe

${ }^{10}$ Resolución 1986/17, de 28 de mayo de 1985.

${ }^{11}$ Cfr. J. Ruiloba Alvariño, «Los Pactos Internacionales de las Naciones Unidas de 16 de diciembre de 1966», en C. Fernández de CASADEvante Romaní (coord.), Derecho Internacional de los Derechos Humanos, Dilex, Madrid, 2007, p. 168. 
precisar en sus informes — que se presentan cada cinco años— las medidas legislativas, judiciales y de todo tipo que haya adoptado para hacer efectivos los derechos enunciados en el Pacto. El «diálogo constructivo» termina con la emisión por parte del Comité, tras el examen del correspondiente informe, de unas «Observaciones y Recomendaciones relativas a los informes de los Estados», que representan la opinión del Comité con relación a la situación del Pacto en un determinado Estado Parte. En el caso de que el Comité estime que un Estado ha violado el Pacto, le insta a que respete de forma inmediata las obligaciones asumidas en virtud de éste.

Las «Observaciones y Recomendaciones» del Comité no tienen fuerza jurídica vinculante pero ponen de manifiesto la opinión del grupo de expertos que lo conforman. Su inobservancia evidenciaría una clara mala fe del Estado Parte del Pacto en el cumplimiento de sus obligaciones ${ }^{12}$.

En esa línea de progresivo reforzamiento y mejora de la protección de estos derechos a los que nos referimos se sitúa el Protocolo Facultativo del PDESC de 2008 que analizaremos en detalle más adelante.

Hasta la fecha, España ha presentado cinco informes periódicos —el último, el 11 de febrero de 2011- Tal y como se desprende de las observaciones finales del Comité al cuarto informe (presentado el 7 de junio de 2004), España cumple con las obligaciones del Pacto por razón de la adopción y aplicación de medidas de distinta naturaleza: legislativas, administrativas, judiciales, institucionales y de cooperación internacional. Los ámbitos en que se recomienda la adopción de medidas son, entre otros, los relativos a: la legalización de inmigrantes indocumentados, la vigilancia de situaciones de racismo o xenofobia, la promoción de la tolerancia intercultural, el suministro de información sobre la población romaní, sobre la coordinación y repartición de competencias y responsabilidades entre los distintos niveles de la Administración (estatal, autonómica y local), la programación para la reducción del desempleo o de la contratación temporal, o el refuerzo de inspecciones en materia de accidentes laborales ${ }^{13}$. Asimismo, debemos apuntar que el Plan de Derechos Humanos de España de 2008, anteriormente

12 Cfr. V. Bou Franch y M. Castillo Daudí, Curso de Derecho Internacional de los Derechos Humanos, Tirant lo Blanch, Valencia, 2010, p. 70.

${ }_{13}$ Para un análisis detallado de los informes periódicos de España ante el Comité de Derechos Económicos, Sociales y Culturales, remitimos al trabajo de A. PASTOR PaLOMAR, «El Comité de Derechos Económicos, Sociales y Culturales», en C. FERnándeZ DE CASAdEvante Romaní (dir.), España y los órganos de control en materia de Derechos Humanos, Dilex, Madrid, 2010, pp. 109-124; obra colectiva que recomendamos para un estudio en profundidad de la práctica española relativa a todos los procedimientos convencionales de control de los derechos humanos. 
referido, prevé como MEDIDA 5 la adopción de un protocolo de actuación para dar cumplimiento a los distintos dictámenes y recomendaciones de los distintos Comités de Protección de los Derechos Humanos de Naciones Unidas. A este respecto se establecerán pautas para tramitar las recomendaciones de dichos Comités con el objeto de proporcionar reparación adecuada a los interesados. No hay duda que semejante proclamación de intenciones resulta bienvenida y apunta en la buena dirección. Ahora bien, no debemos olvidar que la aplicación de tal protocolo de actuación necesitaría de una mejora sustancial en la coordinación administrativa y de los recursos disponibles, algo hasta ahora claramente insuficiente.

\subsection{La Organización Internacional del Trabajo}

Dentro de este mismo ámbito universal onusiano, los derechos socioeconómicos, y, más concretamente, los derechos y libertades fundamentales en el trabajo, son objeto de regulación y protección específica por uno de los organismos especializados de Naciones Unidas, cual es la Organización Internacional del Trabajo (OIT) ${ }^{14}$. Tres son sus mecanismos de actuación: la creación de normas sociales de carácter internacional, por la vía de convenios y recomendaciones ${ }^{15}$; la prestación de asistencia técnica a los Estados para facilitar el progreso social; y la elaboración de estudios que faciliten la acción social de la Organización, sus miembros u otras instituciones en la materia. A los efectos de supervisión de los compromisos asumidos por los Estados miembros, la OIT prevé dos mecanismos de control:

- Sistema de contrwol periódico a través de informes estatales.

- Procedimientos especiales, que incluyen reclamaciones, quejas y un procedimiento especial en materia de libertad sindical.

El mecanismo de control periódico se basa en el examen de las memorias sobre la aplicación por ley y en la práctica que los Estados miembros

${ }^{14}$ La OIT fue creada el 11 de abril de 1919, a la par que la Sociedad de Naciones, erigiéndose así en las primeras organizaciones internacionales de carácter universal. Tras la creación de la Organización de las Naciones Unidas en 1945, la OIT pasó a formar parte del entramado institucional de ésta, convirtiéndose en 1946 en la primera agencia de las Naciones Unidas.

España forma parte de la OIT desde su fundación en 1919, salvo el paréntesis de 1941-1956, reincorporándose nuevamente en 1956 tras ser aceptada como miembro de las Naciones Unidas.

${ }^{15}$ Son 188 convenios que la OIT ha adoptado hasta la fecha (se pueden consultar en http://www.ilo.org/ilolex/spanish/convdisp1.htm) y 200 las recomendaciones (pueden consultarse en http://www.ilo.org/ilolex/spanish/recdisp1.html). 
envían, así como en las observaciones a ese respecto remitidas por las organizaciones de trabajadores y de empleadores. Concretamente, los miembros de la OIT deben mantenerla informada de manera periódica sobre las siguientes cuestiones:

- Una Memoria anual sobre las medidas que haya adoptado para ejecutar los Convenios de la OIT que hubieran ratificado (art. 22 de la Constitución de la OIT). Estas memorias serán redactadas en la forma que indique el Consejo de Administración y deberán contener los datos que éste solicite.

- Informar respecto de los convenios no ratificados con la frecuencia que fije el Consejo de Administración, sobre el estado de su legislación y la práctica en lo que respecta a los asuntos tratados en esos Convenios, precisando en qué medida se ha puesto o se propone poner en ejecución cualquiera de las disposiciones de los mismos e indicando los motivos que impiden su ratificación [art. 19.5.e)].

- Informar al director general de la OIT, con la periodicidad que establezca el Consejo de Administración, sobre el estado de su legislación y práctica en lo que se refiere a los asuntos tratados en las Recomendaciones, precisando en qué medida se han puesto o se propone poner en ejecución las disposiciones de las Recomendaciones, y las modificaciones que se considere necesario hacer a estas disposiciones para adoptarlas o aplicarlas [art. 19.6.d)].

Dos son los órganos encargados de esta supervisión. Por un lado, la Comisión de Expertos en Aplicación de Convenios y Recomendaciones, creada en 1926 y compuesta por veinte juristas eminentes que son nombrados por el Consejo de Administración por periodos de tres años. A la hora de proceder al examen de la aplicación de las normas internacionales del trabajo, esta Comisión efectúa dos tipos de comentarios: observaciones — que se publican en el Informe anual de la Comisión - y solicitudes directas - que se comunican directamente a los gobiernos concernidos- Por otro, la Comisión Tripartita de Aplicación de Convenios y Recomendaciones de la Conferencia Internacional del Trabajo, compuesta por delegados de los gobiernos, de los empleadores y de los trabajadores. Esta Comisión analiza el Informe en un marco tripartito y selecciona del mismo diversos comentarios que serán objeto de debate, pudiendo adoptar conclusiones, recomendando a los gobiernos que arbitren medidas específicas para solucionar un problema o que soliciten asistencia técnica a la OIT; las conclusiones y recomendaciones son objeto de publicación en un Informe anual. 
Por lo que se refiere a los procedimientos especiales, éstos se articulan en tres modalidades. En primer lugar, quejas que un Estado miembro, un delegado a la Conferencia Internacional del Trabajo, o bien el propio Consejo de Administración de la OIT, en el marco de su competencias, pueden interponer contra otro Estado miembro por incumplimiento de algún Convenio que este último hubiere ratificado (arts. 26 a 34). Tras recibir la queja, el Consejo de Administración puede constituir una comisión de encuesta para el caso, compuesta por tres miembros independientes, que será la responsable de realizar una investigación en profundidad de la queja para formular recomendaciones sobre las medidas que deben tomarse para solucionar los problemas planteados por la queja. La comisión de encuesta es el procedimiento de más alto nivel de la OIT y se recurre a él en caso de violaciones graves y persistentes. Hasta la fecha se han presentado veinticinco quejas - ninguna de ellas contra España- y se han creado doce comisiones de encuesta ${ }^{16}$.

En segundo lugar, reclamaciones de organizaciones profesionales de empleadores y trabajadores contra un Estado por incumplimiento de un Convenio Internacional del Trabajo que éste hubiera ratificado (arts. 24 y 25). Debemos señalar que no estamos ante una reclamación individual, sino colectiva, esto es, no es la víctima de la violación la que interpone la reclamación; pero aun así debemos destacar que esta técnica ha supuesto un paso importante en la justiciabilidad de los derechos sociales, siendo referente para otras técnicas similares, como la adoptada por el Consejo de Europa con el Protocolo Adicional a la Carta de Turín de 1995.

Según lo dispuesto en el Reglamento de 1980 este procedimiento consta de tres fases: admisibilidad, fondo y publicación. Las dos primeras son confidenciales.

Primeramente, la Mesa del Consejo de Administración examinará si se cumplen los requisitos de admisibilidad de la reclamación: presentada por escrito; por una organización profesional; debe hacer referencia expresa al art. 24; debe dirigirse contra un Estado miembro de la OIT; debe referirse a un convenio ratificado por el Estado contra el que se reclama, y debe indicar respecto a qué se alega que el Estado no garantiza el cumplimiento efectivo del citado convenio. Si la decisión sobre admisibilidad del Consejo de Administración es positiva, éste designará un Comité que examinará el fondo de la

${ }^{16} \mathrm{Vid}$. la información en http://www.ilo.org/ilolex/cgi-lex/pqconvs.pl?host=status01\& textbase $=$ ilospa\&hitdirection $=1 \&$ hitstart $=0$ \&hitsrange $=1500$ \&highlight $=\&$ context $=\& q u e r$ $\mathrm{y}=\% 23 \mathrm{ANO} \% 3 \mathrm{E} 1900 \& \mathrm{chspec}=30 \& \mathrm{chspec}=15 \&$ query $0=\&$ query $1=\&$ query $2=\& \mathrm{year}=\% 3$ E1900\&title $=\&$ query $3=\&$ sortmacro $=$ sortyear\&submit $=$ Re. 
reclamación. El Comité podrá solicitar informaciones complementarias a las dos partes dentro del plazo que él mismo fije; también se prevé que ambas partes formulen declaraciones orales ante el Comité, así como la posibilidad de visita al lugar por funcionarios de la OIT para investigar los hechos. Finalizado el examen del fondo de la reclamación, el Comité emitirá un informe en el que detallará las medidas adoptadas para examinar la reclamación, presentando sus conclusiones y formulando sus recomendaciones sobre la decisión de fondo que deberá adoptar el Consejo de Administración. La publicación por parte del Consejo de Administración de la reclamación de la organización profesional, de la declaración del Estado denunciado y de sus propias decisiones cierra el procedimiento. Cuatro son las reclamaciones presentadas contra España en virtud del art. $24^{17}$.

Finalmente, debemos referirnos al procedimiento especial de quejas relativo a la libertad sindical y la negociación colectiva. Ambos derechos se encuentran entre los principios fundacionales de la OIT, y tras la adopción de los Convenio núms. 87 y 98 sobre la materia, la OIT llegó a la conclusión de que el principio de libertad sindical requería otros procedimientos de control - al margen de los establecidos en la Constitución de la OITpara garantizar su cumplimiento en los países que no habían ratificado los Convenios pertinentes. Como consecuencia, en 1951 se crea el Comité de Libertad Sindical ${ }^{18}$ — compuesto por un presidente independiente y por tres representantes de los gobiernos, tres de los trabajadores y tres de los empleadores- con el objetivo de examinar las quejas sobre violaciones por algún Estado miembro de la libertad sindical, hubiese o no ratificado los Convenios pertinentes. Estas quejas pueden ser presentadas por organizaciones de empleadores y trabajadores. Si el Comité acepta el caso, se pone en contacto con el gobierno denunciado con la finalidad de que aclare los hechos. Si observa que se ha producido violación de las normas o principios de la libertad sindical, el Comité emite un informe a través del Consejo de Administración y formula recomendaciones al respecto, que son objeto de seguimiento. Hasta la fecha, el Comité de Libertad Sindical ha examinado cerca de 2.500 casos; de ellos, 86 contra España ${ }^{19}$.

17 Vid. http://www.ilo.org/ilolex/spanish/repframeS.htm.

${ }_{18}$ Esta práctica institucionalizada se remonta a 1950 con la creación de la Comisión de Investigación y Conciliación en Materia de Libertad Sindical que, en colaboración con Naciones Unidas, analizaba las reclamaciones por violación del derecho a la libre sindicación que recibía el ECOSOC. El sistema de supervisión de las violaciones de la libre sindicación se completó en 1951 con la creación del Comité de Libertad Sindical.

${ }^{19} \mathrm{La}$ información al respecto puede consultarse en http://www.ilo.org/ilolex/spanish/ digestq.htm. 


\section{Los derechos económicos, sociales y culturales en el ámbito regional}

Pero la labor de promoción y protección de los derechos socioeconómicos no es tarea exclusiva de las Naciones Unidas y resulta igualmente reseñable el papel desempeñado por las Organizaciones internacionales de carácter regional en este ámbito, como es el caso de la Organización de Estados Americanos, si bien destaca a este respecto la labor realizada en el ámbito regional europeo ${ }^{20}$.

\subsection{La protección en el sistema interamericano}

En el sistema interamericano, las bases jurídicas de la protección de los derechos sociales son tres: la Declaración Americana de los Derechos y Deberes del Hombre de 1948, la Convención Americana sobre Derechos Humanos de San José de Costa Rica de 22 de noviembre de 1969 y el Protocolo Adicional a la Convención Americana sobre Derechos Humanos en Materia de Derechos Económicos, Sociales y Culturales, adoptado en San Salvador el 17 de noviembre de 1988 (en vigor desde 1999) ${ }^{21}$. Hay que señalar que hasta la llegada del Protocolo de San Salvador la protección de los derechos sociales en el ámbito interamericano era prácticamente inexistente, pues la Convención de 1969 no contiene en realidad disposiciones relativas a estos derechos, siendo la única alusión y regulación la recogida en el art. 26, según el cual los Estados Partes se comprometen a adoptar medidas - a nivel interno o mediante cooperación internacional — para lograr progresivamente, y en la medida de los recursos disponibles, la plena efectividad de los derechos de carácter económico, social y cultural contenidos en la Carta de la Organización de Estados Americanos —básicamente los derechos del Capítulo VII relativo al «desarrollo integral»-.

${ }^{20}$ El sistema de protección de los derechos sociales en África, centrado en la labor de la Comisión Africana de Derechos Humanos, es prácticamente nulo (vid., a este respecto, I. Comins Mingol, «Los derechos económicos y sociales en África sesenta años después de la Declaración Universal de los Derechos Humanos», Tiempo de Paz, núm. 90, 2008, pp. 40-48). Mientras que, por lo que se refiere al ámbito regional asiático, la protección de estos derechos es absolutamente inexistente.

${ }^{21}$ Un estudio más detallado del sistema interamericano de protección de los derechos sociales puede consultarse en C. TeIJO GARCÍA, «La tutela de los derechos económicos, sociales y culturales en el sistema interamericano: evolución y tendencias», en Congreso Internacional 1810-2010: 200 años de Iberoamérica, pp. 2321-2336 (http://halshs.archivesouvertes.fr/docs/00/53/16/29/PDF/AT16 Teijo.pdf). 
El Protocolo de San Salvador de 1988 amplía y fortalece, como decimos, la protección de los derechos sociales en el sistema interamericano. Tiene el mérito, por un lado, de reconocer finalmente, con carácter jurídicamente vinculante, los derechos económicos, sociales y culturales que proclamara la Declaración Americana de 1948. Concretamente, reconoce los siguientes derechos: derecho al trabajo (art. 6), condiciones justas, equitativas y satisfactorias del trabajo (art. 7), derechos sindicales (art. 8), derecho a la seguridad social (art. 9), derecho a la salud (art. 10), derecho a la alimentación (art. 12), derecho a la educación (art. 13), derecho a los beneficios de la cultura (art. 14), derecho a la constitución y protección de la familia (art. 15), derecho a la niñez (art. 16), protección de los ancianos (art. 17) y protección de los minusválidos (art. 18).

Por otra parte, el Protocolo instaura dos mecanismos de supervisión y control: los informes periódicos y las peticiones individuales. Los primeros vienen regulados en el art. 19, según el cual los Estados están obligados a presentar informes acerca de las medidas progresivas adoptadas para asegurar el respeto de los derechos reconocidos en el Protocolo. El primer informe inicial se presenta al año de la entrada en vigor, los sucesivos cada tres años. El examen de los informes recae en el Consejo Interamericano para el Desarrollo Integral. Igualmente, el Secretario General de la Organización de Estados Americanos transmite copia de los informes a la Comisión Interamericana de Derechos Humanos, que puede formular observaciones y hacer recomendaciones a los Estados sobre la situación de los derechos enunciados en el Protocolo.

El sistema de petición individual está limitado únicamente a dos derechos: libertad sindical (art. 8) y derecho a la educación (art. 13). Las violaciones de estos dos derechos por algún Estado Parte del Protocolo podrán ser denunciadas ante la Comisión Interamericana de Derechos Humanos. Están legitimados para interponer estas peticiones cualquier persona, grupo de personas u ONG, con independencia de que se consideren o no víctimas directas de la violación; esto es, se reconoce la posibilidad de actio popularis, lo que comporta un hito importante en la materia, siendo la única institución que reconoce esta posibilidad en materia de derechos humanos. Si la Comisión confirmara la violación y el Estado denunciado no acatara la eventual resolución de condena dictada por la misma, ésta podrá llevar el asunto ante la Corte Interamericana de Derechos Humanos, cuyas sentencias sí son vinculantes ${ }^{22}$.

22 Para un análisis detallado sobre la jurisprudencia de la Corte Interamericana de 
Dentro de este ámbito interamericano cabría referirse igualmente al Acuerdo de Cooperación Laboral de América del Norte (ACLAN), firmado el 14 de septiembre de 1993 y en vigor desde el 1 de enero de 1994, por el que se establece una zona de libre comercio entre Canadá, Estados Unidos y México, y que crea la Comisión para la Cooperación Laboral ${ }^{23}$. El ACLAN fue el primer acuerdo internacional sobre asuntos laborales ligado a un tratado internacional de libre comercio. El Acuerdo ofrece un mecanismo para que los países miembros garanticen la aplicación efectiva de sus leyes y normas laborales internas, tanto actuales como futuras, sin interferir con el funcionamiento soberano de los diferentes sistemas laborales nacionales, lo que representa un enfoque único y novedoso. Por su parte, la Comisión para la Cooperación Laboral es el único organismo internacional dedicado exclusivamente a los derechos laborales y asuntos relacionados con el trabajo desde la creación en 1919 de la Organización Internacional del Trabajo.

Lo más relevante del ACLAN es que no crea nuevos estándares de protección social internacionales. El compromiso esencial de los Estados es garantizar la efectividad de su propia regulación laboral en once campos definidos por el art. 49 y el Anexo I del Acuerdo, así como promover un alto nivel de su protección legislativa. Esos campos son: libertad de asociación y derecho a organizarse, derecho a la negociación colectiva, derecho a la huelga, prohibición del trabajo forzoso, restricciones al trabajo de menores, condiciones mínimas del trabajo, eliminación de la discriminación en el trabajo, igualdad salarial, prevención de riesgos laborales, compensación en caso de lesiones y protección de los trabajadores migratorios.

Paralelamente, el ACLAN crea un sistema de control del cumplimiento de estas obligaciones que permite iniciar reclamaciones contra un Estado por incumplimiento grave de su legislación nacional. Dos son las vías de actuación. Por un lado, presentación de comunicaciones públicas por cualquier persona o grupo de personas interesadas por la violación de las obligaciones del ACLAN. Por otro, la acción de un Estado miembro que solicite consultas ministeriales a otro por la violación de las obligaciones relativas a cualquiera de los once principios laborales anteriormente men-

Derechos Humanos respecto de los derechos sociales, vid. L. BuRgorgue-Larsen, «Los derechos económicos y sociales en la jurisprudencia de la Corte Interamericana de Derechos Humanos», en A. Embid Irujo (dir.), Derechos económicos y sociales, Madrid, Iustel, 2009, pp. 337-357.

${ }^{23} \mathrm{La}$ información al respecto puede consultarse en http://sp.naalc.org//index.

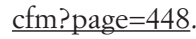


cionados. En ambos casos estamos ante mecanismos de control poco coercitivos destinados a generar, a largo plazo, buenas prácticas nacionales de aplicación de derechos sociales y donde prevalece la negociación colectiva sobre la imposición jurisdiccional ${ }^{24}$.

\subsection{Los derechos socioeconómicos en el ámbito regional europeo: el Consejo de Europa}

$\mathrm{Al}$ aludir a los derechos sociales en el ámbito regional europeo es obligada la referencia al destacado papel jugado en esta materia por la Unión Europea, quien ha realizado una importante labor para conciliar su rápida integración económica con el impulso del progreso social. De hecho, el modelo político europeo persigue que el adelanto económico sea semejante al progreso social, lo que es apreciable no sólo en sus tratados y en la normativa comunitaria, sino en la propia jurisprudencia del Tribunal de Justicia de la Unión Europea (asunto Albany, C-67/96; asunto Dassonville, C-8/74, o Cassis de Dijon, C-120/78).

Por otro lado, debemos tener presente que la Carta de Derechos Fundamentales de la Unión Europea de 18 de diciembre de $2000^{25}$, texto jurídicamente vinculante desde la entrada en vigor del Tratado de Lisboa el 1 de diciembre de 2009, reconoce igualmente importantes derechos socioeconómicos, tales como la libertad profesional y el derecho a trabajar (art. 15), libertad de empresa (art. 16), derecho a la propiedad (art. 17), derecho a la información y consulta a los trabajadores en la empresa (art. 27), derecho de negociación y acción colectiva (art. 28), derecho de acceso a los servicios de colocación (art. 29), protección en caso de despido injustificado (art. 30), condiciones de trabajo justas y equitativas (art. 31), prohibición del trabajo infantil y protección de los jóvenes en el trabajo (art. 32), vida familiar y vida profesional (art. 33), seguridad social y ayuda social (art. 34), protección de la salud (art. 35), acceso a los servicios de interés económico general (art. 36) y protección de los consumidores (art. 38). Sin embargo, a diferencia de otros sistemas institucionales de protección de derechos humanos a los que nos hemos referido en este trabajo, la Unión Europea no ha articulado adecuados mecanismos de control y garantía

${ }^{24}$ Cfr. V. M. SÁNCHEZ, «Globalización y protección internacional de los derechos sociales», en J. Bonet Pérez y V. M. SÁnchez (dirs.), Los derechos humanos en el siglo XXI. Continuidad y cambios, Huygens, 2008, pp. 424-425.

25 2000/C 364/01. 
de la aplicación de estos derechos; más concretamente, en el marco de la Unión Europea no se reconoce la posibilidad de reclamación individual contra un Estado miembro en caso de presunta violación de algunos de estos derechos fundamentales, técnica que es, como ya hemos señalado, la piedra angular de la protección de los derechos humanos. Una deficiencia que resulta, cuando menos, reseñable.

Más destacable es, sin duda, la labor llevada a cabo en este ámbito por el Consejo de Europa. En este sentido, de manera similar a lo que sucede a nivel universal en el ámbito de las Naciones Unidas, el Consejo de Europa articula su sistema de protección de los derechos humanos diferenciando dos categorías de derechos: los derechos civiles y políticos, por un lado, y los derechos económicos, sociales y culturales, por otro; si bien aquí no se abordó la positivación de ambas categorías de forma conjunta, como hemos visto ocurrió en el sistema onusiano, sino que se llevó a cabo claramente de manera distanciada en el tiempo. Resulta así que, mientras los primeros son objeto de protección por el Convenio Europeo para la Salvaguardia de los Derechos Humanos y de las Libertades Fundamentales, firmado en Roma el 4 de noviembre de 1950, los segundos están protegidos por la Carta Social Europea, firmada en Turín el 18 de octubre de 1961 ${ }^{26}$, y en vigor desde el 26 de febrero de 1965. La Carta Social ha sido ratificada, hasta la fecha, por 27 de los 47 Estados miembros del Consejo de Europa $^{27}$. En este sentido, se da la peculiar circunstancia de que, mientras para ser miembro del Consejo de Europa es necesario aceptar el Convenio de Roma de 1950, no ocurre lo mismo con la Carta Social Europea ${ }^{28}$. Esto motiva que no todos los Estados miembros del Consejo de Europa sean partes de la Carta, aunque sí lo son del Convenio de Roma. España

${ }^{26}$ La Carta fue firmada en Turín para conmemorar el centenario de la unificación de Italia.

${ }^{27}$ Estos 27 Estados son: Alemania, Austria, Bélgica, Croacia, Chipre, República Checa, Dinamarca, España, Eslovaquia, ex República Yugoslava de Macedonia, Finlandia, Francia, Grecia, Hungría, Irlanda, Islandia, Italia, Letonia, Luxemburgo, Malta, Noruega, Países Bajos, Polonia, Portugal, Reino Unido, Suecia y Turquía.

${ }^{28}$ Hay que advertir que no se trata de un requisito expresamente recogido en el Estatuto del Consejo de Europa, pero que se viene exigiendo en la práctica desde el ingreso de Portugal en 1976.La necesaria revitalización de la protección de los derechos socioeconómicos y, por ende, de la Carta Social Europea debería pasar por establecer la adhesión a la Carta como requisito para acceder a la membresía del Consejo de Europa. Así se ha manifestado la Asamblea Parlamentaria en su Recomendación 1168 (1991), de 24 de septiembre, relativa al futuro de la Carta Social del Consejo de Europa, en la que afirma que «la aplicación de normas suficientemente próximas en materia de derechos sociales, teniendo en cuenta las circunstancias nacionales, debería ser un criterio de admisión en el Consejo de Europa». 
ratificó la Carta Social Europea el 6 de mayo de 1980, entrando en vigor el 5 de junio de $1980^{29}$.

Cierto es, no obstante, que un primer grupo de derechos sociales o impregnados de una faceta social o prestacional estaban ya incluidos en el propio Convenio de Roma de 1950 y sus primeros Protocolos, sobre todo en el Protocolo Adicional núm. 1, de 20 de marzo de 1952; tal es el caso de la prohibición del trabajo forzoso u obligatorio (art. 4 del Convenio), del derecho a la creación de sindicatos y a la pertenencia a los mismos, incluido dentro del derecho a la libertad de reunión y de asociación (art. 11 del Convenio), de la protección de la propiedad privada (art. 1 del Protocolo núm. 1), o del derecho a la educación (art. 2 del Protocolo núm. 1). Sin embargo, es evidente que se trata de un número muy limitado de derechos, lo cual es de todo punto lógico habida cuenta que el elenco de derechos objeto de protección en el Convenio de Roma se limita de manera fundamental a los derechos civiles y políticos, y no a los derechos socioeconómicos. Ante este evidente déficit se hacía necesario adoptar un tratado que integrara de manera específica y completa los derechos económicos y sociales en el ámbito europeo. Esto tiene lugar con la adopción de la Carta Social Europea en 1961, la cual, en el marco de un importante proceso de evidente revitalización de la protección de los derechos socioeconómicos, ha sido posteriormente completada por el Protocolo Adicional a la Carta Social Europea de 5 de mayo de 1988 (en vigor desde el 4 de septiembre de 1992), que concreta y amplía los derechos en ella reconocidos, y ha sido enmendada por dos Protocolos —uno de 1991 y otro de 1995- que modifican su sistema procesal e institucional. Además, existe una Carta Social Europea Revisada de 3 de mayo de 1996, que entró en

${ }_{29}$ BOE, núm. 153, de 26 de junio de 1980. Al depositar su instrumento de ratificación, España presentó la siguiente declaración:

«España interpretará y aplicará los arts. 5 y 6 de la Carta Social Europea, en relación con el art. 31 y el anexo de la Carta, de manera que sus disposiciones sean compatibles con las de los arts. 28, 37, 103 y 127 de la Constitución española».

Los arts. 5 y 6 de la Carta recogen el derecho sindical y el derecho a la negociación colectiva. Por su parte, los arts. 28 y 103 de la Constitución española se refieren a la posibilidad de limitar o exceptuar por ley el ejercicio del derecho de sindicación de las Fuerzas o Institutos armados o de los demás cuerpos sometidos a disciplina militar, así como a regular las peculiaridades de su ejercicio para los funcionarios públicos. Mientras que el art. 127 de la Constitución establece que jueces, magistrados y fiscales no podrán sindicarse mientras se hallen en activo. El Comité Europeo de Derechos Sociales ha declarado que estas restricciones del derecho de sindicación y negociación colectiva existentes en España resultan conformes con la Carta Social en la medida en que son admitidas para ciertas categorías de funcionarios en el sentido del art. 31 de la Carta [Conclusiones XVIII-1 (España) 2006]. 
vigor el 1 de septiembre de 1999 y que está llamada a sustituir de forma progresiva a la Carta Social de 1961.

La Carta Social Europa es, pues, un tratado de derechos humanos que tiene como objetivo completar a nivel europeo el Convenio de Roma de 1950, constituyendo la contraparte de este Convenio en el ámbito de los derechos económicos y sociales. De esta forma, con la adopción de ambos textos convencionales, el Consejo de Europa confirma la indivisibilidad y la interdependencia de todos los derechos humanos sobre la cual ha tenido ocasión de pronunciarse el propio Tribunal Europeo de Derechos Humanos en su Sentencia de 9 de octubre de 1979, asunto Airey c. Irlanda, en la que advierte que muchos de los derechos civiles y políticos enunciados en el Convenio tienen implicaciones de carácter económico o social. De hecho, esta interconexión le sirve al Tribunal para abrir la puerta a la entrada de los derechos socioeconómicos en el ámbito del Convenio al afirmar que no cree que deba descartarse una interpretación de los derechos consagrados en el Convenio por el simple hecho de que con ello se corra el riesgo de entrar en la esfera de los derechos económicos y sociales, puesto que ningún tabique separa esa esfera del ámbito del Convenio (párrafo 4); una posición reiterada en su jurisprudencia posterior, como lo corrobora la reciente Sentencia de 18 de febrero de 2009, dictada en el asunto Andrejeva c. Letonia, en la que el Tribunal entiende que la negativa por parte de las jurisdicciones letonas de reconocer a la demandante los años trabajados y cotizados antes de 1991 (cuando Letonia pertenecía a la Unión Soviética) a efectos del cálculo de la pensión de jubilación constituye una violación del principio de no discriminación por razón de nacionalidad (art. 14 del Convenio), en conexión con una violación del derecho de propiedad (art. 1 del Protocolo núm. 1). Resulta así que, con esta actitud, el TEDH ha llevado a cabo una encomiable labor en pro de la «justiciabilidad» de los derechos económicos y sociales, que se ha materializado a través de una doble vía de actuación. Por un lado, realizando interpretaciones «extensivas» de algunos de los derechos civiles y políticos recogidos en el Convenio de Roma para entender incluidos derechos sociales - tal es el caso del derecho a la salud, que el Tribunal entiende protegido a través del derecho a la vida—; por otro, aplicando al respecto el principio de no discriminación ${ }^{30}$.

${ }^{30}$ Para un análisis en detalle sobre esta particular labor del Tribunal Europeo de Derechos Humanos, vid. C. Morte GómeZ y S. Salinas Acelga, «Los derechos económicos y sociales en la jurisprudencia del Tribunal Europeo de Derechos Humanos», en A. EMBID Irujo (dir.), Derechos económicos y sociales, Madrid, Iustel, 2009, pp. 359-411. 
Por lo que se refiere a los derechos garantizados, la Carta Social de 1961 reconoce diecinueve derechos económicos y sociales; el Protocolo Adicional de 1988 añade a éstos cuatro derechos; mientras la Carta Revisada de 1996 garantiza otros siete más ${ }^{31}$. El conjunto de todos estos derechos puede clasificarse atendiendo a los siguientes ámbitos materiales:

a) En primer lugar hay que referirse al derecho al trabajo. Este derecho se declara en el art. 1, que lo garantiza sobre la base de cuatro preocupaciones: una política económica y social concebida para asegurar el pleno empleo; derecho del trabajador a ganarse la vida mediante un trabajo libremente elegido, lo que lleva implícita la prohibición del trabajo forzoso; establecimiento de servicios gratuitos de empleo para los trabajadores; promoción de una orientación, formación y readaptación profesionales adecuadas.

b) Condiciones de empleo y despido, a las que se refieren los arts. 2, 3 y 4 de la Carta, así como varios artículos del Protocolo de 1988 y de la Carta Revisada: derecho a unas condiciones de trabajo equitativas; derecho del trabajador a ser informado por escrito, lo más pronto posible, de los aspectos de su contrato o de la relación de trabajo (añadido por la Carta Revisada); derecho a la seguridad y la higiene en el trabajo; derecho a una remuneración equitativa e igual; derecho a la igualdad de oportunidades y de trato en materia de empleo y de profesión, sin discriminación por razón de sexo (art. 1 del Protocolo 1988); derecho de los trabajadores a ser informados y consultados dentro de la empresa (art. 2 del Protocolo 1988); derecho de los trabajadores a tomar parte en la determinación y mejora de las condiciones de trabajo y del entorno laboral en la empresa (art. 3 del Protocolo 1988); derecho a protección en caso de despido, que conlleva el derecho a no ser despedido sin que existan razones válidas relacionadas con sus aptitudes o conducta, y el derecho a indemnización en caso de des-

${ }^{31}$ La puesta en práctica de tales derechos es principalmente una responsabilidad de las autoridades nacionales, quienes, en el marco de su organización constitucional y de su sistema de relaciones sociales, pueden no obstante transferir a las autoridades locales o a los agentes sociales el ejercicio de ciertas competencias en este ámbito. Es evidente que la protección de los derechos socioeconómicos implica, sobre todo, acciones positivas por parte de los Estados. En este sentido, la obligación que incumbe a los Estados Partes de la Carta es la de adoptar no sólo iniciativas jurídicas, sino también iniciativas concretas, esto es, poner los recursos y organizar los procedimientos necesarios que permitan el pleno ejercicio de los derechos reconocidos por la Carta, tal y como ha manifestado el Comité Europeo de Derechos Sociales de forma reiterada [Autismo Europa c. Francia (reclamación núm. 13/2002), decisión de 4 de noviembre de 2003; Movimiento Internacional ATD Cuarto Mundo c. Francia (reclamación núm. 33/2006), decisión de 5 de diciembre de 2007]. 
pido sin causa válida (art. 24 de la Carta Revisada); derecho de los trabajadores a que los créditos derivados de su contrato de trabajo sean garantizados en caso de insolvencia de su empleador (art. 25 de la Carta Revisada), y derecho a la dignidad en el trabajo (art. 26 de la Carta Revisada).

c) Otro grupo es el relativo a los derechos sindicales. Así, el art. 5 se refiere al derecho sindical propiamente dicho y el art. 6 se refiere al derecho de negociación colectiva, incluido el derecho a la huelga. Por su parte, la Carta Revisada añade, a este respecto, el derecho de los representantes de los trabajadores a desempeñar sus funciones, para lo cual los Estados se comprometen a garantizar que en la empresa gocen de una protección efectiva y de facilidades (art. 28). Así como el derecho a información y consulta de los representantes de los trabajadores en los procedimientos de despido colectivo (art. 29).

d) Hay una serie de derechos que tienen como objetivo la protección sociolaboral de ciertos grupos de personas que por diversos motivos necesitan de una especial tutela, en particular con relación al trabajo. Hablamos así de derechos relativos a la protección de los niños y adolescentes (art. 7), del derecho de las trabajadoras a protección (art. 8) y de los derechos de los trabajadores extranjeros que son protegidos de manera específica por los arts. 18 y 19 de la Carta Social.

e) La protección de la familia es objeto específico del art. 16 de la Carta Social. En este sentido, la Carta Social es probablemente el instrumento internacional más implicado en la evolución de las políticas familiares, reconociendo a la familia como «cédula fundamental de la sociedad».

f) Los arts. 9, 10 y 15 de la Carta Social garantizan los siguientes derechos relativos a la formación profesional: derecho a la orientación profesional, derecho a la formación profesional propiamente dicha, derecho de las personas física o psíquicamente disminuidas a la formación profesional y a la readaptación profesional y social.

g) En los arts. 11 a 14 de la Carta Social se garantizan ciertos derechos de protección social, tales como: derecho a la protección de la salud, que conlleva eliminar las causas de una salud deficiente, establecer servicios educacionales y de consulta dirigidos a la mejora de la salud, y prevenir, en la medida de lo posible, las enfermedades epidérmicas, endémicas y otras; derecho a la seguridad social; derecho a la asistencia social y médica; derecho a los beneficios de los servicios sociales. Por su parte, el Protocolo de 1988 incorpora el derecho a la protección social de las personas ancianas que supone, entre otros, el derecho a escoger libremente su modo de vida, a disponer de viviendas apropiadas a sus necesidades, y a la asistencia 
sanitaria. Mientras que la Carta Revisada añade el derecho a la protección contra la pobreza y la exclusión social (art. 30), por el cual los Estados se comprometen a promover el acceso a la vivienda, la formación, la enseñanza, la cultura y la asistencia social y médica de las personas que corran el riesgo de encontrarse en tal situación. Asimismo, la Carta Revisada incorpora al catálogo de derechos socioeconómicos garantizados el derecho a la vivienda (art. 31), que implica el compromiso de los Estados de favorecer el acceso a la vivienda de un nivel suficiente, de prevenir y paliar la situación de carencia de hogar, y de hacer asequible el precio de la vivienda a las personas que no dispongan de recursos suficientes.

Si comparamos los derechos reconocidos en la Carta Social con los correspondientes del Pacto de Derechos Económicos, Sociales y Culturales de Naciones Unidas, podemos observar que la Carta es más completa en cuanto a la protección de ciertos derechos, tales como el derecho de negociación colectiva, el derecho a la protección de los niños y adolescentes, y de los trabajadores migrantes y sus familias. Sin embargo, es necesario señalar que el espíritu de la Carta Social se centra sobre todo en los derechos sociales, mientras que el Pacto engloba los derechos económicos, sociales y culturales. Resulta así que este último pone el acento en la cooperación internacional y contiene ciertos derechos no previstos en la Carta, tales como el derecho a la educación gratuita y el derecho a la participar en la vida cultural y en el progreso científico. De igual manera que, a sensu contrario, hay ciertos derechos de la Carta que no están reconocidos en el Pacto, como son la protección en caso de despido injustificado, el derecho de negociación y acción colectiva, el derecho de huelga, y la consulta y participación de los trabajadores.

Por otra parte, es importante destacar que estos derechos reconocidos por la Carta son objeto de un particular sistema de aceptación de las obligaciones jurídicas, que constituye uno de los aspectos más singulares de la Carta. De acuerdo con lo estipulado en el art. 20.1, se permite a los Estados contratantes, en el momento de ratificar la Carta, la posibilidad de aceptación parcial de las disposiciones de la Carta, e incluso de sus párrafos, esto es, que los Estados pueden obligarse sólo por algunos de los derechos recogidos en la Carta y no por todos ${ }^{32}$. A través de esta fórmula de

${ }^{32}$ La posibilidad del consentimiento en obligarse sólo para algunas partes de un tratado internacional, tal y como dispone el art. 20 de la Carta, es una posibilidad prevista por el art. 17 de la Convención de Viena sobre Derecho de los Tratados de 1969, que exige para ello que lo permita el propio tratado o que los Estados contratantes lo convengan. Esta particu- 
«ratificación a la carta» se trata de facilitar la incorporación de los Estados a la Carta Social permitiéndoles elegir de antemano y libremente los derechos que están dispuestos a reconocer y garantizar, aunque puede plantear algunos inconvenientes, en particular, la tentación de algunos Estados de intentar salvar sus puntos deficitarios a través de la aceptación de los artículos que no exigen demasiados esfuerzos, al mismo tiempo que da lugar a un sistema fragmentado o atomizado que menoscaba la integridad de la Carta, generando una pluralidad de regímenes jurídicos o de tantas «Cartas Sociales» como Estados lleguen a ser partes que, sin duda, resta eficacia a la propia Carta considerada en su conjunto ${ }^{33}$.

Ahora bien, este sistema de aceptación está sometido a unas condiciones. Así, se configura un «núcleo duro» de derechos que todos los Estados deben reconocer y garantizar al ratificar la Carta Social. A este respecto, se señalan siete artículos de la Parte II: 1 (derecho al trabajo), 5 (derecho sindical), 6 (derecho de negociación colectiva), 12 (derecho a la seguridad social), 13 (derecho a la asistencia social y médica), 16 (derecho de la familia a una protección social, jurídica y económica) y 19 (derecho de los trabajadores migrantes y sus familias a protección y asistencia). De estos siete artículos, los Estados deben obligarse al menos por cinco. Junto a este mínimo fijo común, los Estados contratantes deben aceptar también un número adicional de artículos o de párrafos numerados de la Parte II, siempre que el número total de los artículos y de los párrafos numerados a los que quede obligado cada Estado no sea inferior a diez artículos o a cuarenta y cinco párrafos numerados. Con tan peculiar sistema de aceptación pueden darse situaciones tan paradójicas como que eligiendo cuarenta y cinco párrafos numerados, los Estados sólo se estén obligando realmente por ocho artículos, o que al aceptar párrafos numerados resulte que dentro de un mismo derecho de los que se reconocen en un artículo de la Carta se acepten sólo algunas de sus manifestaciones. Esto significa que del total de diecinueve artículos de la Carta que recogen los derechos protegidos, un Estado podría obligarse únicamente por trece.

Otro elemento igualmente diferenciador de la Carta Social es el relativo a su aplicación territorial. Según el art. 34, la Carta se aplica en el territorio metropolitano de cada Estado contratante. A los efectos de lo que deba

laridad de la aceptación parcial también la encontramos en el Convenio núm. 102 de la OIT y en el Código Europeo de Seguridad Social.

${ }_{33}$ Cfr. C. M. DíAz BARRADO, «La Carta Social Europea: un instrumento para el desarrollo de los derechos sociales en Europa», en Política Social Internacional y Europea, Madrid, Ministerio de Trabajo y Asuntos Sociales, 1996, p. 249. 
entenderse por territorio metropolitano, cada Estado signatario, mediante una declaración dirigida al Secretario General del Consejo de Europa, podrá especificar en el momento de la firma o de la ratificación el territorio que ha de entenderse como tal. Como ejemplos de este tipo de declaraciones de aplicación territorial podemos referir la de Dinamarca, según la cual el territorio metropolitano de Dinamarca excluye a las Islas Feroe y a Groenlandia, o la de Noruega que excluye de la consideración de territorio metropolitano a Svalbard (Spitzberg) y a Jan Mayen. No obstante esta aplicación territorial, el art. 34.2 prevé la posibilidad de que los Estados, bien en el momento de ratificación de la Carta, bien en un momento posterior, hagan una declaración extendiendo la aplicación de ésta a territorios no metropolitanos, en concreto a territorios cuyas relaciones internacionales tengan a su cargo o respecto de los cuales dicho Estado asuma sus responsabilidades internacionales. En dicha declaración se especificará qué artículos o párrafos de la Parte II se aceptan como obligatorios con relación a dichos territorios no metropolitanos incluidos en la declaración. Una declaración de este tipo fue la realizada en 1963 por Reino Unido, en la que declara que la Carta se aplica a la isla de Mann, o la efectuada por Países Bajos en 1985, según la cual la Carta se aplicará a las Antillas holandesas y a Aruba, a partir del 1 de enero de 1986.

Finalmente, resulta igualmente reseñable la «peculiar» regulación de su aplicación ratione personae establecida en el punto 1 del Anexo de la Carta. De acuerdo con el tenor de esta disposición, cada Estado se compromete a aplicar las disposiciones de los arts. 1 a 17 a sus nacionales, y por lo que se refiere a los extranjeros, nacionales de otros Estados contratantes de la Carta, sólo estarán protegidos por dichos artículos en el caso de que los mismos residan legalmente o que trabajen de forma regular en su territorio. Esta limitación del ámbito de aplicación personal de la Carta resulta cuando menos sorprendente en un tratado de protección de derechos humanos, y constituye una auténtica particularidad de la Carta Social, pues no la encontramos en ningún otro instrumento internacional similar. Muy al contrario, tanto el Pacto de Derechos Económicos, Sociales y Culturales de Naciones Unidas, como los Convenios de la OIT, lo que establecen es el principio de no discriminación sin límites ${ }^{34}$. Esta limitación del ámbito personal de aplicación no opera, sin embargo, en el

${ }^{34}$ Así lo recoge expresamente el art. 2.2 del Pacto de Derechos Económicos, Sociales y Culturales de Naciones Unidas. Tampoco encontramos semejante limitación personal en el Convenio de Roma de 1950, cuyo art. 14 consagra, por el contrario, el disfrute de todos los derechos recogidos en el Convenio por todas las personas sin ningún tipo de distinción. 
caso del derecho a la seguridad social y del derecho a la asistencia social y médica, dado que los arts. 12.4 y 13.4 de la Carta consagran el principio de igualdad de trato entre todos los nacionales de los Estados contratantes con relación a estos dos derechos. Dentro de este ámbito de aplicación personal, mención particular merecen aquellos que tengan la condición de refugiado, conforme a lo dispuesto por la Convención de Ginebra relativa al Estatuto de los Refugiados de 28 de julio de 1951, y que tengan su residencia regular en el territorio de un Estado Parte, pues según el punto 2 del Anexo dicho Estado les concederá el trato más favorable posible, lo que supone que se extienden a los mismos todas las garantías ofrecidas por la Carta ${ }^{35}$.

\section{LOS MECANISMOS DE PROTECCIÓN DE LOS DERECHOS SOCIOECONÓMICOS EN EL MARCO DE LAS NACIONES UNIDAS: EL PROTOCOLO FACULTATIVO DEL PACTO DE DERECHOS ECONÓMICOS, SOCIALES Y CULTURALES DE 10 DE DICIEMBRE DE 2008}

Tal y como ya hemos advertido, hasta la llegada del Protocolo Facultativo del Pacto de Derechos Económicos Sociales y Culturales ${ }^{36}$ existía un importante déficit en la protección de los derechos humanos por lo que a los derechos económicos, sociales y culturales se refiere, al carecer de una adecuado sistema de control de su aplicación que se limitaba a la técnica de los informes estatales periódicos que ya hemos visto. Dicha carencia queda finalmente paliada, a nivel universal, con la adopción de este Protocolo al establecer la posibilidad de interponer una denuncia individual en caso de violación de los derechos económicos, sociales y culturales que el Pacto de 1966 reconoce. Se equipara así a estos derechos con los derechos civiles y políticos, y se homologa también al Comité de Derechos Económicos, Sociales y Culturales con el resto de órganos de derechos humanos establecidos en tratados internacionales que sí tienen competencia para conocer de quejas individuales. De esta forma, con la entrada en escena de este Protocolo se consigue finalmente la consagración del postulado de la indivisibilidad e interdependencia de todos los derechos humanos, tal y

${ }^{35}$ Los anexos del Protocolo Adicional a la Carta Social Europea de 1988 y de la Carta Social Revisada de 1996 extienden este mismo trato a los apátridas en el sentido de la Convención de Nueva York de 28 de septiembre de 1954.

${ }^{36}$ Ibid.. 
como viene formulada en la Declaración Universal de los Derechos Humanos de 1948, y se reconoce, por primera vez, en una norma convencional universal la plena justiciabilidad de los derechos económicos, sociales y culturales.

\section{El largo camino recorrido hasta la adopción del Protocolo}

El 10 de diciembre de 2008, coincidiendo con el sexagésimo aniversario de la Declaración Universal de los Derechos Humanos, la Asamblea General de Naciones Unidas aprobó por consenso, en el transcurso de la 63. a sesión ordinaria, la Resolución A/RES/63/117 por la que se adoptaba el Protocolo del PDESC, texto que había sido previamente elaborado en el seno del Consejo de Derechos Humanos. No obstante, el camino a recorrer fue arduo, fruto de una compleja labor iniciada en 1990.

Es en esa fecha, coincidiendo con la caída del muro de Berlín y el fin de la guerra fría, cuando el Comité de Derechos Económicos, Sociales y Culturales comienza a debatir la posibilidad de redactar un Protocolo Facultativo del PDESC. No hay duda que el contexto sociohistórico había sufrido un cambio radical. En su momento, los derechos sociales — también llamados, como hemos apuntado, «derechos de segunda generación»- fueron considerados derechos progresivos por naturaleza, demasiado imprecisos para ser judicialmente aplicables, y estrechamente vinculados con la tradición socialista — de hecho, sus máximos defensores eran los Estados del bloque soviético-; todo ello motivó esa postergación de la que fueron objeto. Ante un nuevo escenario, el planteamiento es igualmente cambiante, lo que da lugar al inicio de un largo y difícil proceso codificador que ha necesitado toda una serie de etapas.

Como señalábamos, es en 1990, en el seno del Comité de Derechos Económicos, Sociales y Culturales, cuando se abre el debate acerca de la conveniencia de un Protocolo Facultativo del PDESC que recoja la técnica de la comunicación individual respecto de estos derechos.

En 1993 se celebra la Conferencia Mundial sobre Derechos Humanos en la que se adopta la «Declaración y Programa de Acción de Viena», y en la que se reafirma la indivisibilidad de todos los derechos humanos, alentando tanto a la Comisión de Derechos Humanos como al Comité de Derechos Económicos, Sociales y Culturales a seguir evaluando la elaboración del Protocolo Facultativo del PDESC. Pero no es hasta 1997 cuando el Comité de Derechos Económicos, Sociales y Culturales finaliza un pri- 
mer borrador que fue sometido a la consideración de la Comisión de Derechos Humanos, quien, a su vez, se lo envió a los Estados y ONGs para que hicieran las oportunas observaciones.

La Comisión de Derechos Humanos nombró, en 2001, un experto independiente para que analizara la cuestión; el nombramiento recayó en el tunecino señor Kotrane. Un año más tarde, el señor Kotrane entregó un primer informe en el que recomendaba el establecimiento de un sistema de quejas individuales que se articularía a través de un Protocolo Facultativo del PDESC. Ese mismo año 2002, la Comisión decidió crear un grupo de trabajo para analizar esa cuestión.

El grupo de trabajo llegó a celebrar tres periodos de sesiones, en 2004, 2005 y 2006, sin que se obtuviera ningún resultado visible. Sólo cuando la Comisión de Derechos Humanos desaparece en 2006 y es sustituida por el Consejo de Derechos Humanos se consigue desbloquear la cuestión al crear un nuevo grupo de trabajo, esta vez de composición abierta, para que redacte el Protocolo.

El 4 de abril de 2008, tras cinco periodos de sesiones, ese nuevo grupo aprueba un Protocolo Facultativo que había sido presentado por su presidenta-relatora, la señora Catarina de Alburquerque (Portugal) ${ }^{37}$. Tras recibir el informe definitivo, dicho Protocolo fue aceptado por el Consejo de Derechos Humanos el 18 de junio de $2008^{38}$, nada menos que dieciocho años después de su inicio, lo cual pone de manifiesto la encarnizada resistencia de algunos Estados en admitir que los derechos económicos, socia-

37 Vid. Doc. A/HRC/8/WG.4/3, de 28 de febrero de 2008, Anexo.

Existen varios trabajos, anteriores a la adopción del Protocolo en 2008, que analizan el proceso de elaboración del mismo, así como los proyectos anteriores que se fueron presentando; entre ellos, puede consultarse el estudio realizado por M. ZANI, «Vers une protection internationale efficace des droits économiques, sociaux et culturels: la nécessité d'une protocole facultatif au Pacte onusien de 1966 prévoyant un système de plaintes», Revue de droit international de sciences diplomatiques et politiques, vol. 85.2, 2007, pp. 135-157. Entre los estudios posteriores a la aprobación del texto en 2008 destacan los trabajos de F. J. Quel LóPEZ, «Un paso esencial hacia la eficacia internacional de los derechos económicos, sociales y culturales. Luces y sombras del Protocolo Facultativo del Pacto de Derechos Económicos, Sociales y Culturales», en A. EmBiD Inujo (dir.), Derechos económicos y sociales, Madrid, Iustel, 2009, pp. 305-334, y C. Villán Durán, «Protocolo Facultativo del Pacto Internacional de Derechos Económicos, Sociales y Culturales», Revista Española de Desarrollo y Cooperación, núm. 23, 2009, pp. 39-40, así como el monográfico del Nordic Journal of Human Rights, vol. 27, núm. 1, 2009, editado bajo el título Perspectives on a New Complaint and Inquiry Procedure: The Optional Protocol to the International Covenant on Economic, Social and Cultural Rights.

${ }^{38}$ La documentación relativa al Consejo de Derechos Humanos puede consultarse en la siguiente dirección web: http://portal.ohchr.org. 
les y culturales son justiciables. De hecho, podemos apuntar como Estados claramente contrarios al establecimiento de un sistema de quejas individuales y, por tanto, a la adopción de este Protocolo, a: Australia, Canadá, Estados Unidos, Japón, Polonia, Reino Unido, Corea y Suiza. En cambio, se mostraron claramente a favor: Alemania, Argentina, Chile, Costa Rica, Croacia, Cuba, España, Etiopía, Francia, Finlandia, Indonesia, México, Perú, Portugal, Irán, Eslovenia y Venezuela.

No obstante, pese a tales reticencias, como hemos señalado el Protocolo Facultativo del PDESC vio finalmente la luz el 10 de diciembre de 2008, quedando abierto a la firma el 24 de septiembre de 2009 en un acto solemne celebrado en el marco de la jornada anual de las Naciones Unidas de «Ceremonia de tratados de 2009: hacia la participación y aplicación universales». Veinte fueron los Estados que decidieron firmar el Protocolo el mismo día 24 de septiembre; en los días sucesivos se fueron uniendo otros, de tal forma que, hasta el momento, contamos con treinta y seis Estados signatarios ${ }^{39}$. La puerta ha quedado finalmente abierta a la necesaria y trascendental entrada en vigor. Sólo queda esperar que de esos treinta y seis Estados, diez de ellos se decidan —una vez superados sus respectivos trámites internos- a depositar el correspondiente instrumento de ratificación que dé lugar a la plena vigencia jurídica de este Protocolo $^{40}$. Como ya hemos apuntado, hasta la fecha lo han hecho tres: Ecuador fue el primero en hacerlo, el 11 de junio de 2010; tras él Mongolia, el 1 de julio de ese mismo año; mientras que España ratificó el Protocolo el 23 de septiembre de 2010.

39 Toda la información actualizada de los Estados signatarios y contratantes de este Protocolo, así como el texto del mismo, puede consultarse en la siguiente página web de Naciones Unidas sobre tratados: http://treaties.un.org/Pages/ViewDetails. aspx? src $=$ TREATY \&mtdsg no $=I V-3-$ a\&chapter $=4 \&$ lang $=$ en.

${ }^{40} \mathrm{El}$ art. 17 del Protocolo dispone: «1. El presente Protocolo estará abierto a la firma de cualquier Estado que haya firmado el Pacto, lo haya ratificado o se haya adherido a él.

2. El presente Protocolo estará sujeto a ratificación por cualquier Estado que haya ratificado el Pacto o se haya adherido a él. Los instrumentos de ratificación se depositarán en poder del Secretario General de las Naciones Unidas.

3. El presente Protocolo quedará abierto a la adhesión de cualquier Estado que haya ratificado el Pacto o se haya adherido a él».

Por su parte, el art. 18 establece que el Protocolo entrará en vigor a los tres meses del depósito del décimo instrumento de ratificación o adhesión. 


\section{Algunos aspectos destacables de este Protocolo}

Decíamos que con este tratado se equiparan los mecanismos de control entre unos y otros derechos, y se homologa al Comité de Derechos Económicos, Sociales y Culturales con otros comités de derechos humanos creados convencionalmente en el marco de Naciones Unidas. Ahora bien, creemos necesario poner de manifiesto que con este Protocolo se ha hecho un importante esfuerzo de progreso, se ha ido más allá, de tal forma que nos encontramos con significativas diferencias reseñables si comparamos el Protocolo Facultativo del Pacto de Derechos Económicos, Sociales y Culturales de 2008 con otros tratados de derechos humanos, y más concretamente con el Protocolo Facultativo del Pacto de Derechos Civiles y Políticos de 1966 (PDCP), que fue el texto que se tomó como referente. Cinco son las diferencias más notables entre ambos textos convencionales.

Así, por un lado, mientras respecto de los derechos civiles y políticos existen tres mecanismos de control —informes periódicos, quejas interestatales y comunicaciones individuales-, con el Protocolo del PDESC son cuatro los sistemas de garantía que se articulan respecto de los derechos económicos, sociales y culturales. En efecto, junto a los informes periódicos que recoge el art. 16 del PDESC, el Protocolo añade las quejas interestatales, las comunicaciones particulares y un cuarto sistema de control más, cual es la investigación confidencial. Este mecanismo no existe, como decimos, en el PDCP; de hecho, sólo existe respecto de la Convención contra la Tortura de 1984 y de la Convención sobre la eliminación de todas las formas de discriminación contra la mujer de 1979.

Por otra parte, se simplifica el procedimiento en lo que se refiere a las denuncias interestatales al establecer una única fase procedimental más sencilla en vez de las dos complejas fases que existen respecto de los derechos civiles y políticos.

Por lo que se refiere a las comunicaciones individuales introduce igualmente una importante novedad, cual es la posibilidad de que el Comité de Derechos Económicos, Sociales y Culturales intente un arreglo amistoso entre las partes a lo largo del procedimiento.

Como diferencia notable debemos indicar que el Protocolo del PDESC nuevamente innova al establecer una norma protectora general de los derechos bumanos a nivel convencional. Tal es la que viene recogida en el art. 13 que obliga a los Estados a adoptar medidas para que «las personas que se hallen bajo su jurisdicción no sean sometidas a ningún tipo de malos tra- 
tos o intimidación como consecuencia de cualquier comunicación con el Comité de conformidad con el presente Protocolo». Esta medida de protección es de aplicación respecto de los tres mecanismos de control que establece el Protocolo del PDESC, esto es, denuncias interestatales, comunicaciones individuales e investigación confidencial.

Finalmente, el Protocolo otorga específicamente una competencia al Comité de Derechos Económicos, Sociales y Culturales que no tiene reconocida expresamente su homólogo el Comité de Derechos Humanos, ni en el PDCP, ni en su Primer Protocolo Facultativo. Tal es que dicho Comité podrá recomendar en sus dictámenes «la necesidad de asesoramiento técnico o de asistencia» al Estado afectado, tal y como establece el art. 14. En este caso, con el consentimiento de dicho Estado, podrá transmitir sus recomendaciones de asesoramiento a los organismos especializados, fondos y programas de Naciones Unidas, con el fin de adoptar medidas internacionales que puedan ayudar a los Estados Partes a hacer valer de forma más efectiva los derechos reconocidos en el PDESC. Sin duda alguna estamos ante una importante competencia con la que se quiere paliar la falta de atención que han tenido durante más de cuatro décadas los derechos económicos, sociales y culturales. En esta línea, resulta aún más destacable la previsión final que recoge este mismo art. 14, cuál es la creación de un Fondo Fiduciario de Naciones Unidas por el que se financiarán estas actividades de asistencia técnica. Porque, evidentemente, para fomentar el desarrollo de estos derechos económicos, sociales y culturales — como son tener seguridad social, asistencia médica o enseñanza gratuita- se necesita dinero, y resulta que donde menos desarrollados están este tipo de derechos es precisamente en los países más pobres, en los Estados en desarrollo, los cuales carecen de capacidad económica para hacer frente al necesario progreso que exige la adecuada protección de tales derechos ${ }^{41}$. De ahí que la creación de este Fondo suponga un avance notable y una muestra del compromiso que, por fin, parecen haber asumido los Estados por promocionar los derechos económicos.

${ }^{41}$ Las cifras son elocuentes, una quinta parte de la población en desarrollo está hambrienta, la cuarta parte no tiene ni siquiera acceso al agua y la tercera parte se halla en estado de absoluta pobreza. 


\section{Las denuncias interestatales y la investigación confidencial}

El art. 10 del Protocolo regula la competencia del Comité de Derechos Económicos, Sociales y Culturales para recibir comunicaciones de un Estado Parte del Protocolo contra otro Estado Parte por incumplimiento de las obligaciones recogidas en el PDESC. Esta competencia tiene, no obstante, carácter facultativo, lo que significa que deberá ser expresamente aceptada por los Estados Partes interesados. El procedimiento es confidencial y consta de dos fases. En la primera se intenta el arreglo pacífico de la controversia entre los dos Estados. Si en seis meses no se consigue, cualquiera de ellos puede remitir el asunto al Comité, iniciándose la segunda fase. Lo primero que debe hacer el Comité es verificar que se ha agotado la vía interna, si es así, ofrecerá sus buenos oficios para arreglar la diferencia. Si los buenos oficios fracasan, el Comité emitirá un informe en el que se expondrán los hechos, las alegaciones de las Partes y las observaciones que estime pertinentes hacer a los Estados.

La investigación confidencial viene regulada en los arts. 11 y 12 , y también es un procedimiento facultativo, de tal forma que sólo obligará a los Estados que hubieran aceptado la competencia del Comité para esta técnica. El Comité procederá a realizar una investigación confidencial cuando reciba información fidedigna acerca de que se han producido violaciones graves o sistemáticas por un Estado Parte del Protocolo de cualquiera de los derechos reconocidos en el Pacto de Derechos Económicos, Sociales y Culturales. Desde el inicio del procedimiento el Comité invitará al Estado investigado a colaborar en el examen de la información a esos efectos y a presentar sus observaciones sobre dicha información. El Comité encargará el asunto a uno o más de sus miembros quienes emitirán un informe, pudiendo visitar el territorio del Estado investigado, con su consentimiento. El informe es examinado por el Comité, quien transmitirá sus conclusiones al Estado investigado, junto con las observaciones y recomendaciones que estime oportunas. El Estado dispondrá de seis meses para hacer sus propias observaciones. El Comité podrá incluir un resumen de los resultados en su informe anual; podrá, igualmente, hacer un seguimiento del cumplimiento de sus observaciones por parte del Estado investigado a través de los informes periódicos.

Como ya hemos indicado, esta última técnica existe ya respecto de la Convención contra la tortura y la Convención contra la discriminación de la mujer, revelando una escasa utilidad en la práctica. Es de lamentar el 
carácter confidencial del procedimiento, su lentitud y la escasa información que se hace pública al respecto ${ }^{42}$.

\section{Las reclamaciones individuales por violación del Pacto de Derechos Económicos, Sociales y Culturales}

Bajo este procedimiento, una persona o grupo de personas que se consideren víctimas de la violación de alguno o algunos de los derechos consagrados en el PDESC por parte de algún Estado Parte de dicho Pacto están legitimadas para presentar una reclamación ante el Comité de Derechos Económicos, Sociales y Culturales. Su funcionamiento viene regulado en los arts. 2 a 9 del Protocolo.

Las comunicaciones deberán presentarse por escrito ante la Secretaría del Comité en la Oficina del Alto Comisionado de las Naciones Unidas en Ginebra. Cabe la posibilidad de remitir las quejas por correo electrónico, si bien, en este caso, dichas quejas deberán remitirse igualmente en papel, debidamente firmadas por el denunciante. El idioma que puede utilizarse al efecto puede ser cualquiera de los idiomas oficiales de trabajo del Comité: ruso, inglés, francés, español o chino (el árabe no lo es).

Básicamente, las fases del procedimiento son seis que se articulan de la siguiente manera.

1. Competencia. Lo primero que tiene que hacer el Comité es verificar su competencia, tanto desde un punto de vista temporal - los hechos denunciados han debido tener lugar después de la entrada en vigor del Protocolo-, como desde un punto de vista personal —el denunciante debe ser una persona o grupo de personas bajo la jurisdicción del Estado denunciado en el momento de producirse la violación-, y desde un punto de vista material — debe tratarse de la violación de derechos reconocidos en el PDESC-.

2. Verificada su competencia, el Comité debe entrar a valorar la admisibilidad de la comunicación, esto es, que se cumplan los requisitos de admisibilidad que señalan los arts. 2 y 3 del Protocolo. Los requisitos son los siguientes:

- La queja se debe presentar por escrito.

- No debe ser anónima.

${ }^{42}$ Cfr. C. Villán Durán, «Protocolo Facultativo...», op. cit., pp. 39-40. 
- La debe presentar directamente la víctima o su representante legal. No se admite, por tanto, la actio popularis. Debemos igualmente tener presente que sólo se admite como víctima a una persona o grupo de personas, no están tampoco legitimadas las ONGs, salvo que actúen en representación de la víctima. Aunque no dice nada el Protocolo, podemos aventurar que bajo el concepto de «víctima» deberá incluirse tanto la víctima directa como la indirecta, e incluso la víctima potencial, tal y como viene sucediendo con las denuncias individuales por violación de los derechos civiles y políticos.

- La comunicación deber estar bien fundamentada, es decir, debe expresar claramente el artículo o artículos del Pacto de Derechos Económicos, Sociales y Culturales que han sido violados, y esa alegación debe corroborarse con las pruebas que se presenten junto a la reclamación.

- No debe ser abusiva, no debe constituir abuso de derecho. Es decir, que la víctima, amparándose en este derecho de queja, no puede extralimitarse en sus reclamaciones aludiendo a hechos que en sí mismos no son una violación.

- Que el mismo asunto no haya sido conocido ya por el Comité, ni haya sido o esté siendo conocido por otro órgano de control internacional de los derechos humanos; es la regla ne bis in idem.

- Por último, el previo agotamiento de los recursos en el orden interno del Estado denunciado. Existe un plazo de un año para presentar la reclamación desde que se agotó la vía interna, plazo que, en cambio, no existe respecto de los derechos civiles y políticos.

3. Si los requisitos no se cumplen, la comunicación se declara inadmisible y termina el proceso. Pero si es admitida, el Comité da traslado de la misma al Estado denunciado, de forma confidencial, para que en un plazo de seis meses presente por escrito cuantas aclaraciones o explicaciones desee, así como la relación de las medidas que sobre el caso concreto hubiere adoptado.

4. Llegados a este punto, el Comité intentará primeramente un arreglo amistoso, para lo cual pondrá sus buenos oficios a disposición de las partes para que lleguen a un acuerdo. Si dicho acuerdo se logra finaliza el procedimiento.

5. Pero si no es así, el Comité pasará a examinar el fondo del asunto a la luz de todos los documentos que le hayan presentado las Partes y emitirá un dictamen con relación a la comunicación, así como las recomendaciones que hace al Estado denunciado. 
6. Por último, el Protocolo del PDESC introduce una fase final que tampoco aparece recogida de forma expresa en el Protocolo del PDCP - aunque en la práctica sí se lleva a cabo-, cual es la del seguimiento al Estado denunciado de que está siguiendo las observaciones que le ha hecho el Comité. A estos efectos, el art. 9 establece que en un plazo de seis meses, el Estado enviará por escrito toda la información pertinente acerca de las medidas que ha adoptado para cumplir las recomendaciones del Comité. Posteriormente, el Comité podrá volver a pedirle más información si lo estima oportuno.

El seguimiento del cumplimiento de las recomendaciones, tanto de éste, como de otros comités de derechos humanos existentes en el marco de Naciones Unidas (discriminación racial, derechos humanos, tortura, etc.), se convierte en un elemento clave de presión sobre el Estado denunciado y, por ende, de garantía de acatamiento, ya que debemos tener presente que, a diferencia de las sentencias del Tribunal Europeo de Derechos Humanos o de la Corte Interamericana de Derechos Humanos, las decisiones de estos comités no son jurídicamente vinculantes, ya que no estamos ante órganos jurisdiccionales.

\section{EL SISTEMA DE CONTROL DEL CONSEJO DE EUROPA: LA CARTA SOCIAL EUROPEA Y SUS PROTOCOLOS}

Tal y como sucede con la mayoría de los tratados internacionales relativos a la protección de los derechos humanos, la Carta Social Europea de 1961 acompaña el reconocimiento de los derechos con un sistema de control de respeto efectivo de los derechos proclamados. En este sentido, la Carta de 1961 prevé un único mecanismo de supervisión a través del cual se verifica que los Estados Partes ofrecen garantías suficientes para asegurar el debido cumplimiento de los compromisos asumidos al obligarse por la Carta, basado en la obligación de presentación de informes estatales periódicos, tanto sobre las disposiciones aceptadas (art. 21), como respecto de aquellas que no hubieran sido aceptadas (art. 22). Unos y otros son examinados por dos órganos de control: el Comité de Expertos Independientes —actual Comité Europeo de Derechos Sociales-y el Subcomité del Comité Social Gubernamental del Consejo de Europa — actual Comité Gubernamental— (art. 27).

No obstante, esta técnica ha sido objeto de modificación a través del Protocolo de Enmienda a la Carta Social Europea hecho en Turín el 21 de 
octubre de 1991 con el que se pretende mejorar el mecanismo de los informes periódicos, delimitando mejor las competencias de los dos principales órganos de control —el Comité de Expertos Independientes y el Comité Gubernamental—, y clarificando su papel en este ámbito. Con relación a este Protocolo es necesario señalar que, aunque formalmente no ha entrado en vigor - pues al ser una enmienda necesita la unanimidad de todos los Estados Partes de la Carta y lo han ratificado veintitrés de los veintisiete Estados Partes de la misma— ${ }^{43}$, en la práctica su contenido está siendo aplicado desde diciembre de 1991 por una decisión del Comité de Ministros mediante la que pedía a los órganos de control de la Carta que aplicaran este Protocolo incluso antes de su entrada en vigor, en la medida en que el texto de la Carta lo permitiera ${ }^{44}$. De esta forma, todas las disposiciones del Protocolo de 1991 están siendo aplicadas progresivamente desde entonces, excepto la que se refiere a la elección de miembros del Comité Europeo de Derechos Sociales por la Asamblea Parlamentaria (éstos siguen siendo elegidos por el Comité de Ministros). Las modificaciones introducidas por este Protocolo se refieren a la desaparición de la Asamblea Parlamentaria del procedimiento de examen de los informes, así como a la delimitación más clara de las competencias jurídicas del Comité Europeo de Derechos Sociales respecto de las competencias políticas del Comité Gubernamental.

A diferencia del Convenio de Roma de 1950, la Carta Social no recoge sistema alguno de demandas ni de denuncias ante un órgano jurisdiccional o cuasi-jurisdiccional; ni tampoco es posible el recurso al Tribunal Europeo de Derechos Humanos en caso de violación de alguno de los derechos recogidos en la Carta. La falta de tal mecanismo de control, que sí existe respecto de los derechos civiles y políticos, supone un evidente déficit proteccionista que se ha intentado justificar avocando, como ya hemos apuntado, una diferente naturaleza de los derechos socioeconómicos frente a aquéllos, que los harían no justiciables o de difícil justiciabilidad; un razonamiento cuando menos cuestionable.

Con el objetivo de paliar ese déficit y reforzar el sistema de control instaurado por la Carta de 1961 se adoptó el Protocolo Adicional de 9 de

${ }^{43}$ Estos 23 Estados son: Austria, Bélgica, Croacia, Chipre, República Checa, Dinamarca, Finlandia, Francia, Grecia, Hungría, Irlanda, Islandia, Italia, Letonia, Malta, Países Bajos, Noruega, Portugal, República Eslovaca, España, Suecia, ex República Yugoslava de Macedonia y Turquía. España depositó su instrumento de ratificación el 24 de enero de 2000.

${ }^{44}$ Decisión adoptada en diciembre de 1991 con motivo de la 467. . Reunión de los Delegados de los Ministros. 
noviembre de 1995, que establece un nuevo procedimiento de control basado en la posibilidad de interponer reclamaciones colectivas sobre la aplicación insatisfactoria de la Carta que viene a completar al tradicional de los informes estatales periódicos. En este sentido, el Protocolo Adicional a la Carta Social Europea estableciendo un Sistema de Reclamaciones Colectivas, adoptado el 22 de junio de 1995 y abierto a la firma el 9 de noviembre de 1995, tiene por objeto mejorar el respeto de los derechos sociales reconocidos por la Carta. A este respecto introduce, como decimos, el nuevo mecanismo de control de la aplicación de los derechos recogidos en la Carta, cual es el de las reclamaciones colectivas, que viene a unirse al clásico de los informes estatales. El Protocolo permite que organizaciones nacionales e internacionales de trabajadores y empresarios, así como organizaciones no gubernamentales, presenten reclamaciones colectivas ante el Comité Europeo de Derechos Sociales alegando una aplicación no satisfactoria de la Carta. Este Protocolo entró en vigor el 1 de julio de 1998, una vez conseguidas las cinco ratificaciones requeridas. Hasta la fecha sólo cuenta con catorce Estados Partes ${ }^{45}$. España ni ha firmado, ni ha ratificado este Protocolo Adicional de 1995.

\section{Los órganos de control}

En el sistema de supervisión y control de la Carta, tal y como se encuentra actualmente articulado tras las modificaciones introducidas por los Protocolos de 1991 y 1995, intervienen en mayor o menor medida tres órganos principales del Consejo de Europa: la Asamblea Parlamentaria, el Secretario General y, sobre todo, el Comité de Ministros ${ }^{46}$. Además intervienen de forma más directa otros dos órganos específicos: el Comité Europeo de Derechos Sociales y el Comité Gubernamental.

${ }^{45}$ Los Estados que han aceptado someterse a este mecanismo de control de las reclamaciones colectivas son: Bélgica, Croacia, Bulgaria, Chipre, Finlandia, Francia, Grecia, Irlanda, Italia, Países Bajos, Noruega, Portugal, Eslovenia y Suecia.

${ }^{46}$ La Asamblea Parlamentaria es el órgano plenario y deliberativo del Consejo de Europa; está compuesta por representantes de los Parlamentos de los Estados miembros del Consejo de Europa. El Secretario General es elegido por la Asamblea Parlamentaria por un periodo de cinco años; asume la responsabilidad global de la orientación estratégica del programa de trabajo y del presupuesto del Consejo de Europa, y controla la gestión día a día de la organización. El Comité de Ministros lo componen los ministros de Asuntos Exteriores de los Estados miembros del Consejo de Europa o sus delegados o representantes permanentes en Estrasburgo; es el órgano decisorio de la Organización. 
a) El Comité Europeo de Derechos Sociales. Es el nombre que recibe desde el año 2000 el antiguo Comité de Expertos Independientes ${ }^{47}$. Según el art. 25 de la Carta, el Comité estaría compuesto por siete miembros elegidos por el Comité de Ministros ${ }^{48}$, sin embargo, el Protocolo de 1991 modifica este extremo estableciendo que el número mínimo de miembros del Comité será de nueve, siendo decisión del Comité de Ministros fijar su número exacto (art. 3 del Protocolo 1991). Actualmente el Comité Europeo de Derechos Sociales está compuesto por quince miembros ${ }^{49}$. Éstos son elegidos de entre una lista de expertos independientes, de máxima integridad y de competencia reconocida en cuestiones sociales internacionales, propuestos por las partes contratantes. Son nombrados por un periodo de seis años, renovable sólo una vez. Los miembros del Comité pueden ser de la nacionalidad de cualquier Estado miembro del Consejo de Europa aunque no sea parte de la Carta Social, no pudiendo haber más de un miembro de la misma nacionalidad. Los miembros del Comité actúan a título individual y durante su ejercicio no pueden asumir funciones incompatibles con las exigencias de independencia, imparcialidad y disponibilidad inherentes a su cargo. El Comité puede a su vez crear en su seno subcomités de un mínimo de tres miembros con la finalidad de preparar sus decisiones (art. 20 del Reglamento). Es asistido en sus funciones por un secretario compuesto por agentes del Consejo de Europa.

El Comité celebra siete sesiones al año en la sede del Consejo de Europa en Estrasburgo. Cada miembro del Comité es relator para un cierto número de disposiciones de la Carta y para ciertas reclamaciones. Los informes estatales son examinados por dos subcomités, cada uno de ellos es responsable de un cierto número de disposiciones; los subcomités preparan los trabajos del Comité plenario. En cambio, las reclamaciones colectivas son examinadas por el Comité plenario.

b) El Comité Gubernamental. Es el nombre con el que se designa desde 1991 al antiguo Subcomité del Comité Social Gubernamental, conforme a la nomenclatura del Protocolo de 1991. Según el art. 27 de la Carta, está constituido por un representante de cada uno de los Estados de 2000).

${ }^{47}$ El cambio se produjo a partir del ciclo XV-1 de control de los informes (marzo-junio

${ }_{48}$ Cuando entre en vigor el Protocolo de 1991 los miembros del Comité Europeo de Derechos Sociales serán elegidos por la Asamblea Parlamentaria. Éste es el único punto que no se aplica del Protocolo que, aunque no está vigente, se aplica desde 1991 por decisión del Comité de Ministros.

${ }^{49}$ El número fue fijado por decisión del Comité de Ministros adoptada en la $751 .^{a}$ Sesión de Delegados de Ministros (2-7 de mayo de 2001). 
Partes de la Carta Social, e invitará, como máximo, a dos organizaciones internacionales de empleadores y a dos organizaciones internacionales de trabajadores para que, como observadores, participen a título consultivo en sus reuniones. Podrá además convocar para consulta a un máximo de dos representaciones de organizaciones internacionales no gubernamentales (ONGs) reconocidas como entidades consultivas por el Consejo de Europa sobre cuestiones respecto de las cuales tales organizaciones estén especialmente calificadas, como, por ejemplo, el bienestar social o la protección económica y social de la familia. Tras las modificaciones introducidas por el Protocolo de 1991 se ha eliminado la restricción del máximo de dos ONGs.

\section{La técnica de los informes estatales periódicos}

Conforme a un procedimiento clásico en Derecho internacional, los Estados Partes de la Carta Social tienen la obligación de presentar regularmente informes sobre la forma en que aplican las disposiciones de la Carta. Esta obligación de informes periódicos afecta tanto a las disposiciones de la Parte II que el Estado haya aceptado (art. 21), como a aquellas que no hubiera aceptado en el momento de la ratificación o aprobación o en una notificación posterior (art. 22). Mientras los informes relativos a las disposiciones aceptadas tienen una periodicidad de dos años — son bienales-, la periodicidad de los relativos a las no aceptadas no está expresamente determinada por la Carta, siendo competencia del Comité de Ministros decidir cuándo es necesaria su presentación, así como la forma que deben tener los mismos. El Protocolo Adicional de 1988 y la Carta Revisada de 1996 prevén también este mecanismo de control.

Este sistema inicial de presentación de informes se ha visto, no obstante, modificado por una decisión del Comité de Ministros de 3 de mayo de 2006 —adoptada sobre la base de una propuesta del Comité Gubernamental de 2005- en vigor a partir de 2007 (el último informe presentado con el anterior sistema es de 21 de marzo de 2006). Según el nuevo sistema, los Estados presentarán antes del 31 de octubre de cada año un informe anual sobre una parte de las disposiciones de la Carta (ya sea de la de 1961, ya sea de la Revisada), que se reagrupan por materias en cuatro grupos temáticos. De esta forma, cada disposición de la Carta será objeto de un informe cada cuatro años. Los cuatro grupos de disposiciones son los siguientes: 
- Grupo 1: empleo, formación e igualdad de oportunidades (arts. 1, $9,10,15,18,20,24$ y 25$)$.

- Grupo 2: sanidad, seguridad social y protección social (arts. 3, 11, $12,13,14,23$ у 30$)$.

- Grupo 3: derechos relativos al trabajo (arts. 2, 4, 5, 6, 21, 22, 26, 28 y 29 ).

- Grupo 4: infancia, familia y migrantes (arts. 7, 8, 16, 17, 19, 27 у 31).

Los informes son elaborados sobre la base de un formulario adoptado por el Comité de Ministros que contiene para cada disposición una lista de cuestiones a las que los Estados deben responder. Asimismo, los Estados tienen la obligación de responder a las cuestiones específicas planteadas por el Comité. Para cada una de las disposiciones aceptadas de la Carta, los Estados deben remitir toda la información pertinente acerca de las medidas adoptadas para asegurar su aplicación, precisando concretamente el marco jurídico - textos legislativos o reglamentarios, convenios colectivos u otras disposiciones que contribuyan a esta aplicación-, la jurisprudencia, las medidas adoptadas — reglamentos administrativos, programas, planes de acción, proyectos...- para poner en práctica el marco jurídico y los datos estadísticos que permitan apreciar en que medida se aplican las disposiciones.

Los Estados Partes remitirán sus informes ${ }^{50}$ al Secretario General del Consejo de Europa. Asimismo, los Estados enviarán copia de sus informes a las organizaciones nacionales que estén afiliadas a las organizaciones internacionales de empleadores y trabajadores que sean invitadas a hacerse representar en las reuniones del Comité Gubernamental, para que formulen, si lo desean, sus propias observaciones, que serán transmitidas directamente al Comité Europeo de Derechos Sociales (art. 23). El art. 1 del Protocolo de 1991 prevé igualmente que el Secretario remita una copia de los informes a las ONGs con estatuto consultivo ante el Consejo de Europa y particularmente cualificadas en las materias reguladas por la Carta Social, para que puedan formular también sus observaciones.

El Secretario General transmite los informes estatales presentados al Comité Europeo de Derechos Sociales para su examen (art. 24), el cual tiene en cuenta todas las observaciones y comentarios que hubiera recibido al respecto. Igualmente tomará en cuenta en su apreciación los documen-

${ }^{50}$ Los informes estatales son públicos desde su llegada al Consejo de Europa y pueden consultarse por Internet en la siguiente dirección: http://www.coe.int $/ \mathrm{t} / \mathrm{dghl} / \mathrm{monitoring} /$ socialcharter/Reporting/StateReports/Reports en.asp. 
tos procedentes de las investigaciones efectuadas por sus miembros o por su Secretario, referentes, entre otras, a la doctrina, la jurisprudencia o las informaciones de carácter estadístico, así como informaciones procedentes de otras Organizaciones internacionales, en particular, de las Naciones Unidas, la Unión Europea y la OCDE. La OIT juega un papel específico en la materia, puesto que un representante suyo es observador en el Comité y mantiene a éste informado de los resultados alcanzados dentro de esta organización. Asimismo, el Comité podrá dirigirse directamente a un Estado, si lo considera necesario, para pedirle informaciones y precisiones adicionales. Con toda esta documentación, el Comité Europeo de Derechos Sociales emitirá sus conclusiones acerca de si las disposiciones de la Carta Social están siendo o no aplicadas por el Estado Parte.

Las conclusiones del Comité Europeo de Derechos Sociales se transmiten a la Asamblea Parlamentaria del Consejo de Europa y al Comité Gubernamental. Originariamente, estos dos órganos examinaban tanto el informe estatal como las conclusiones del Comité Europeo de Derechos y emitían su propia opinión al respecto. Sin embargo, la dilación que esta intervención comportaba al mecanismo, unido al hecho de que se generaban conclusiones contradictorias entre estos órganos (motivadas, sin duda, por su diferente composición independiente o gubernamental), determinó que desde 1993 se decidiera aplicar la enmienda que introducía al respecto el Protocolo de 1991. De esta forma, según el art. 27 enmendado, el Comité Gubernamental preparará las decisiones del Comité de Ministros. En particular, a la vista de los informes de los Estados y del Comité Europeo de Derechos Sociales, seleccionará de manera motivada aquellas situaciones que, a su juicio, deberían ser objeto de recomendaciones dirigidas a los Estados. El Comité Gubernamental presentará al Comité de Ministros un informe que se hará público. Finalmente, sobre la base de este informe, el Comité de Ministros adoptará por una mayoría de dos tercios de los votantes (sólo los Estados Partes de la Carta tienen derecho de voto) una resolución relativa al conjunto del ciclo de control, la cual contendrá recomendaciones individuales dirigidas al Estado.

Por su parte, según el art. 29 enmendado, el Secretario General del Consejo de Europa remitirá a la Asamblea Parlamentaria los informes del Comité Europeo de Derechos Sociales y del Comité Gubernamental, así como las resoluciones del Comité de Ministros con vistas a los debates periódicos en sesión plenaria.

Entre 1982 y 2010, España ha presentado 23 informes sobre la aplicación de la Carta, el último ha sido sometido el 2 de noviembre de 2010 
con relación al grupo temático 4. El 17 de diciembre de 2010 se publicó el informe del Comité Europeo de Derechos Sociales relativo al grupo temático 3 , y en él se señala como dato negativo más reseñable que el salario mínimo en España, fijado en 629 euros en 2009, no se ajusta a la Carta Social por ser «manifiestamente injusto» y «muy bajo» ${ }^{51}$.

\section{El mecanismo de las reclamaciones colectivas}

El mecanismo de control de las reclamaciones colectivas viene regulado por el Protocolo Adicional de 1995, que entró en vigor el 1 de julio de 1998. Se trata de un Protocolo facultativo por lo que queda a la discrecionalidad de los Estados Partes de la Carta Social aceptarlo o no; hasta la fecha, son catorce los Estados que han aceptado este mecanismo. A través de esta técnica los Estados Partes reconocen el derecho de formular reclamaciones ante el Comité Europeo de Derechos Sociales alegando una aplicación no satisfactoria de la Carta por su parte. Su procedimiento se desarrolla de la siguiente manera.

a) La legitimación activa para interponer estas reclamaciones la ostentan, según los arts. 1 y 2 del Protocolo:

- Las organizaciones internacionales de empleadores y de trabajadores invitadas a participar a título consultivo en los trabajos del Comité Gubernamental. Tres son las organizaciones que entran en este ámbito: la Confederación Europea de Sindicatos (CES), la Unión de Confederaciones de Industria y Empresarios de Europa (UNICE) y la Organización Internacional de Empleadores (OIE).

- Otras ONGs internacionales que gocen de estatuto consultivo en el Consejo de Europa y que estén inscritas en la lista establecida a estos efectos por el Comité Gubernamental (actualmente son 73).

- Las organizaciones nacionales representativas de empleadores y trabajadores pertenecientes a la parte contratante implicada en la reclamación de que se trate.

- Aquellas ONGs nacionales representativas expresamente legitimadas al efecto por un Estado contratante, bien en el momento de prestar

${ }^{51}$ Los comentarios con relación a España y su aplicación de la Carta Social pueden consultarse en el documento público en la dirección: http://www.coe.int/t/dghl/monitoring/ socialcharter/CountryFactsheets/Spain en.pdf. 
el consentimiento, bien en otro momento posterior, que dependan de su jurisdicción y que estén particularmente cualificadas en las materias que se rigen por la Carta. Sólo Finlandia ha procedido a legitimar a sus ONGs a este respecto.

Según lo dispuesto por el art. 3, la legitimación activa de las ONGs no es absoluta, pues éstas sólo podrán presentar reclamaciones colectivas en aquellos ámbitos y respecto de aquellas cuestiones en las que estén particularmente cualificadas.

Queda claro del tenor del Protocolo que está excluida la legitimación activa del individuo - por ello la denominación de reclamaciones colectivas-, lo que diferencia de forma sustancial a este sistema tanto del existente respecto de los derechos civiles y políticos, que sí legitima al individuo, víctima de una presunta violación de sus derechos fundamentales, a demandar al Estado autor de la misma ante el Tribunal de Estrasburgo, como del que hemos visto recoge, en el marco de las Naciones Unidas, el Protocolo Facultativo al Pacto de Derechos Económicos, Sociales y Culturales de 10 de diciembre de 2008.

Por lo que se refiere a la legitimación pasiva, se podrá interponer este tipo de reclamaciones colectivas únicamente contra aquellos Estados que, o bien son Partes del Protocolo de 1995, o bien han hecho la declaración unilateral de aceptación de esta técnica prevista en el art. D2 de la Carta Revisada de $1996^{52}$.

b) En cuanto al objeto de las reclamaciones colectivas, éstas deben versar sobre una disposición de Carta Social de 1961 —o del Protocolo de 1988 o de la Carta Revisada, en su caso- que haya sido aceptada por el Estado Parte implicado (art. 4). En ella se debe indicar en qué medida ese Estado no ha respetado la aplicación de esa disposición de una manera satisfactoria. Por razón de su carácter colectivo, no se pueden plantear situaciones individuales de violación de alguno o algunos de los derechos garantizados por la Carta, es decir, la reclamación ha de referirse a una situación general de no conformidad con alguna disposición de la Carta de la legislación o la práctica del Estado.

c) Por lo que se refiere a los aspectos formales, la reclamación debe presentarse por escrito y dirigirse al Secretario General del Consejo de Europa que acusará recibo, informará al Estado implicado y la dará trasla-

52 Doce son los Estados que han ratificado el Protocolo de 1995 y otros dos han hecho la declaración de aceptación de este mecanismo prevista en la Carta Revisada (Bulgaria y Eslovenia). 
do de forma inmediata al Comité Europeo de Derechos Sociales. No existe un formulario para presentar una reclamación colectiva, pero en términos generales la reclamación debe contener la siguiente información:

- el nombre y los datos de contacto de la organización que presenta la reclamación;

- si se trata de una ONG, mención del estatuto consultivo del Consejo de Europa y de la inscripción de la lista establecida por el Comité Gubernamental, así como los ámbitos para los que está cualificada;

- debe aportarse una prueba de que la persona que presenta y firma la queja está autorizada a representar a la organización que presenta la reclamación;

- el Estado contra el que se dirige la reclamación;

- una indicación de la disposición o disposiciones de la Carta presuntamente vulneradas;

- el objeto de la reclamación, es decir, el punto o los puntos con respecto de los cuales el Estado en cuestión ha incumplido presuntamente las disposiciones de la Carta, junto con los argumentos pertinentes y los documentos con que se fundamenta la reclamación.

La reclamación debe redactarse en inglés o en francés en el caso de que sea presentada por alguna de las organizaciones internacionales legitimadas; si es presentada por alguna de las organizaciones nacionales legitimadas, entonces puede redactarse en la lengua oficial, o en una de las lenguas oficiales del Estado en cuestión.

d) Una vez recibida la reclamación por el Comité Europeo de Derechos Sociales, éste decidirá sobre su admisibilidad, previa solicitud, si lo estima pertinente, al Estado implicado o al reclamante de que aporten informaciones y comentarios al respecto. El Protocolo no contiene de forma explícita una lista de los requisitos de admisibilidad, aunque del articulado del mismo, así como de la práctica seguida sobre este punto por el Comité, se puede afirmar que para que la reclamación sea declarada admisible debe cumplir todos los aspectos formales anteriormente reseñados. Además, el Comité deberá verificar si la reclamación es admisible tanto desde un punto de vista personal como material, esto es, que el Estado reclamado haya aceptado este mecanismo de control y que las disposiciones supuestamente violadas hayan sido aceptadas por el mismo. A diferencia de otros mecanismos de control, no se exige el previo agotamiento de los recursos en el orden interno, ni tampoco parece regir el principio non bis in idem, requisitos que sí rigen respecto de las denuncias individuales. 
Las decisiones sobre admisibilidad son adoptadas en un plazo que oscila entre los dos y los seis meses, y son definitivas. Si la reclamación se declara inadmisible, se rechaza y finaliza el procedimiento.

e) Si el Comité Europeo de Derechos Sociales decide que la reclamación es admisible lo pondrá en conocimiento de los Estados Partes de la Carta Social a través del Secretario General y entrará en el fondo, iniciándose a partir de ese momento un procedimiento contradictorio y escrito, aunque si el Comité lo estima oportuno puede celebrar también una audiencia pública. A estos efectos, el Comité pedirá al Estado implicado y a la organización reclamante que le sometan por escrito, y en un plazo determinado por el propio Comité, todas las explicaciones o informaciones apropiadas al caso. Asimismo, pedirá en el mismo plazo a los demás Estados Partes del Protocolo que realicen, si lo desean, las observaciones que estimen convenientes. En el caso de que la reclamación haya sido presentada por alguna de las organizaciones nacionales legitimadas al efecto, el Comité pondrá la reclamación en conocimiento de las organizaciones internacionales de empleadores y de trabajadores invitadas a participar a título consultivo en los trabajos del Comité Gubernamental para que hagan, si quieren, observaciones en el plazo fijado por el Comité. En el caso de que éstos realicen observaciones, el Estado implicado y la organización reclamante podrán presentar informaciones u observaciones suplementarias en el plazo que fije el Comité.

Sobre la base de todo este material escrito, de la audiencia pública en su caso y del proyecto de informe preparado por el relator nombrado el efecto, el Comité delibera en privado sobre el fondo y adopta sus conclusiones sobre el fondo de la reclamación, que permiten deducir si el Estado reclamado ha cumplido o no de manera satisfactoria la aplicación de la disposición de la Carta a que se refiere la reclamación. Las conclusiones del Comité son enviadas a las partes interesadas, al Comité de Ministros y a la Asamblea Parlamentaria en un informe firmado por el presidente, el relator y el secretario, el cual se hace público. Las conclusiones del Comité son adoptadas - en un plazo que oscila entre los seis y los nueve meses-, normalmente, por unanimidad, si bien es posible adoptarlas por mayoría; en este caso el Reglamento del Comité prevé que los miembros que han votado en contra de una conclusión sobre el fondo puedan formular una opinión disidente que se publica junto con el informe que contiene las conclusiones.

f) Finalmente, sobre la base del informe del Comité Europeo de Derechos Sociales, el Comité de Ministros adopta una Resolución por mayo- 
ría simple. En el caso de que se hubiera constatado una aplicación insatisfactoria de la Carta, el Comité de Ministros adoptará, por mayoría de dos tercios, una Recomendación dirigida al Estado implicado para que tome medidas específicas para una correcta aplicación de la Carta Social. La Resolución y la Recomendación, en su caso, del Comité de Ministros se hacen públicas junto con el informe del Comité Europeo de Derechos Sociales en un plazo máximo de cuatro meses desde el envío de este último. A partir de ese momento, el Estado está obligado a facilitar indicaciones acerca de las medidas que haya tomado para cumplir con la Recomendación del Comité de Ministros en el siguiente informe periódico que tiene que dirigir al Secretario General en aplicación del art. 21 de la Carta.

Hasta la fecha se han interpuesto sesenta y seis reclamaciones colectivas. La primera, el 12 de octubre de 1998 contra Portugal, por no ser conforme su práctica con el art. 7.1 de la Carta Social que prohíbe el trabajo a los menores de quince años; la última, el 21 de febrero de 2011 contra Grecia. De los catorce Estados que han aceptado este mecanismo de control sólo Chipre y Noruega no han sido objeto aún de reclamación colectiva alguna; por el contrario, el más denunciado ha sido Francia contra el que se han interpuesto veintitrés reclamaciones ${ }^{53}$.

\section{UNA VALORACIÓN FINAL A MODO DE CONCLUSIÓN}

No hay duda de que, hoy día, existe un reconocimiento general acerca de la necesaria promoción y protección de los derechos socioeconómicos, y prueba de ello es su consagración en tratados internacionales jurídicamente vinculantes que cuentan con una amplia aceptación por parte de los Estados. Sin embargo, el grado de compromiso de éstos queda cuestionado cuando se entra en el análisis detallado de estos tratados y se descubre que la proclamación de tales derechos no va acompañada de un adecuado y eficaz sistema que garantice su aplicación, pues ninguno de ellos permite que, en caso de violación, la víctima, esto es, el individuo que ha visto vulnerados sus derechos, pueda actuar a nivel internacional denunciando al Estado infractor. Estamos ante un evidente déficit proteccionista que, en cambio, no acusan los derechos civiles y políticos respecto de los

53 Toda la documentación relativa a las reclamaciones colectivas es publicada por el Consejo de Europa y puede verse: http://www.coe.int/t/dghl/monitoring/socialcharter/ Complaints/Complaints en.asp. 
cuales se ha llegado, incluso, a articular la posibilidad de demandas individuales ante tribunales internacionales.

Ante este panorama, la adopción y apertura a la firma del Protocolo Facultativo del Pacto de Derechos Económicos, Sociales y Culturales de 10 de diciembre de 2008, que amplía el sistema de control de estos derechos incluyendo la posibilidad de denuncias individuales, no es sino motivo de satisfacción, debiendo felicitarnos por su llegada. Ahora bien, no todo el camino está recorrido, queda aún el mayor de los obstáculos, cual es conseguir que diez Estados demuestren de forma fehaciente su compromiso por la defensa de estos derechos ratificando el Protocolo. Será en ese momento, al entrar en vigor, cuando realmente hayamos conseguido dar un gran paso adelante en la protección de los derechos económicos, sociales y culturales, y se habrá conseguido un nuevo e importante logro en el acceso del individuo a la justicia internacional. 